\title{
Promulgación y juramento de la Constitución de 1869
}

\section{Promulgation and Oath-taking of the 1869 Constitution.}

\author{
José Manuel Mesa Göbel ${ }^{1}$ \\ mesagobel@gmail.com
}

Recepción: 30/10/18 Revisión: 08/11/18 Aceptación: 17/12/18 Publicación: 28/12/18

\section{Resumen}

Todo cambio de régimen en un Estado viene acompañado por trascendentes modificaciones en el ceremonial, el protocolo, sus símbolos, y en la configuración y ejecución de actos, como medio definidor y de legitimación de un nuevo régimen político y de ruptura con el anterior. En el mes de junio de 1869 se van a desarrollar una serie de actos y eventos, ya provengan de la propia iniciativa política como desde planteamientos populares que asume el poder político como vehículo de legitimación del nuevo estado político. Entre esos actos que se llevaron a cabo en ese mes en Madrid, destaca el acto solemne de promulgación y juramento de la Constitución de 1869, el cual tendrá su propia traslación a las distintas capitales de provincia y localidades relevantes, y que tras el análisis del presente estudio se podrá comprobar la profusa regulación normativa que la toma en consideración del juramento de la Norma Fundamental tuvo en numerosas instituciones, miembros y empleados de las mismas. Se trata por tanto de un acto fundamental, con un desarrollo destacado en su ceremonial tanto respecto al acto celebrado el 6 de junio de 1869 en las Cortes Constituyentes, como en todos aquellos actos que consecuencia del juramento afectará a instituciones, sus funcionarios tanto civiles como militares y otros miembros de los mismos. Se trata de una sucesiva y larga serie de disposiciones publicadas en la Gaceta de Madrid, que se alargarán hasta finales del año 1870, abarcando aspectos fundamentales del juramento, su ceremonial, fórmula, y distintos aspectos relacionados con el mismo, así como las consecuencias de no hacerlo. Por tanto, uno más de los actos y eventos solemnes que se desarrollaron en Madrid en ese mes de junio de 1869 como la inauguración del

\footnotetext{
${ }^{1}$ Doctorando en la UNED, programa de doctorado en Derecho y Ciencias Sociales, bajo la dirección de la profesora Dolores del Mar Sánchez González. Licenciado en Derecho, UNED; Máster Universitario en Protocolo, Comunicación y Relaciones Externas, Universidad de Las Palmas de Gran Canaria; Especialista Universitario en Protocolo y Ceremonial del Estado e Internacional, Universidad de Oviedo; Experto Universitario en Relaciones Institucionales y Protocolo, UNED.
} 
Panteón Nacional, el descubrimiento de la escultura de Mendizábal, el nombramiento del Regente y su juramento de la constitución, etc.

Palabras clave: Acto, Constitución, Cortes, ceremonial, juramento, promulgación, solemne.

\begin{abstract}
Every new regime brings along transcendent modifications in a state's ceremonial, protocol, symbols, configuration and performance of ceremonies, so as to define and legitimize the new political regime while rupturing with the previous one. In June 1869, a series of ceremonies and events originated either from political initiative alone or from popular approaches that accepted political power as a means to legitimize the new political state. One of those remarkable ceremonies that were held in Madrid that month was the solemn act of promulgation and oath-taking of the 1869 Constitution, then replicated throughout all capital and major cities in the provinces. As analyzed in this study, the oath-taking of the Fundamental Law allowed for a profuse set of normative regulations that affected a number of institutions along with their members and officials. It was therefore a fundamental act carried out with outstanding formalities at the ceremony held at the Constituent Parliament on June 6,1869 , and in all the resulting ceremonies concerning institutions, their civil and military officials and other members thereof. A long, sequential series of provisions were published in the Madrid Gazette until the end of 1870 to cover key aspects of oath-taking, such as its ceremonial and process, and the consequences of not carrying it out. Therefore, this oath-taking was one of the solemn ceremonies and events that took place in Madrid back in June 1869, together with the inauguration of the National Pantheon, the unveiling of Mendizábal's statue, the appointment of the Regent and his constitutional oath, and so on.
\end{abstract}

Keywords: Ceremony, Constitution, Parliament, ceremonial, oath, promulgation, solemn.

\title{
Sumario
}

1. Introducción.

2. Promulgación de la Constitución de 1869.

3. Pórtico de las Cortes Constituyentes: Acto de promulgación de la Constitución.

4. Sede de las Cortes: Acto de juramento del Poder Ejecutivo de la Ley Fundamental.

5. Los actos de promulgación en distintas ciudades del territorio nacional.

6. El juramento de la Constitución por el Regente.

7. Los Ministerios y el juramento de la norma fundamental de 1869.

8. El Consejo de Estado.

9. La Ley de 18 de diciembre de 1869.

10. La Iglesia y el juramento de la constitución de 1869.

11. Conclusiones.

12. Bibliografía.

13. Recursos bibliográficos y digitales. 


\section{INTRODUCCIÓN}

Durante el mes de junio del año 1869 se van a desarrollar en Madrid a iniciativa del Gobierno Provisional y de las Cortes Constituyentes tres efemérides destacadas en esta primera etapa del Sexenio Democrático tras la Revolución de Septiembre y que se van plasmar en la ejecución de varios actos de relevancia pública y de confirmación del régimen instaurado, efectuándose los mismos en un espacio limitado y corto de tiempo lo que va a producir una saturación de grandes ceremonias que afectarán a Madrid y que producirán una considerable asistencia y participación popular. Así pues van a confluir en un intervalo corto de tiempo tres acontecimientos destacables; el 6 de junio de 1869 tendrá lugar la promulgación y juramento de la Constitución, apartado al que corresponde el presente artículo, el viernes 18 de junio tendrá lugar el acto de juramento del general Serrano como Regente y el domingo 20 de junio se verificará la inauguración del Panteón Nacional, aunque debemos de indicar que dicho acto se configuró en un primer momento como complementario al acto de proclamación y juramento de la Constitución, pero se verá aplazada en dos ocasiones.

El acto de promulgación y juramento de la Constitución de 1869 tendrá lugar el 6 de junio en el Palacio de las Cortes Constituyentes, la promulgación en el pórtico del mismo y dirigido a todas los presentes autoridades y ciudadanía y el juramento en la sede de las Cortes con el ceremonial debido en el Salón de Plenos. Lo que es destacable respecto al juramento en sí de la norma fundamental, es la profusa y sucesiva aparición y publicación de disposiciones en la Gaceta de Madrid que afectan a numerosas instituciones y sus miembros y empleados, ya se encuentren activos, cesantes, jubilados, enfermos o residan en España o en el extranjero para que verifiquen de forma expresa el juramento de la Constitución. Se trata de una ingente producción de leyes, decretos, órdenes, circulares, anuncios oficiales, etc, y que abarcará casi un año, toda vez que la producción normativa llegará hasta septiembre de 1870 .

\section{PROMULGACIÓN DE LA CONSTITUCIÓN DE 1869}

\subsection{Acto solemne de la firma de la Constitución del Estado por los Diputados}

Este acto solemne se llevará a cabo el 2 de junio de $1869^{2}$ en las Cortes, su Presidente de será quien iniciará el mismo con la siguiente alocución: "Siendo llegada la hora señalada ayer para proceder a la firma de los ejemplares de la Constitución, se va a empezar este acto". Se disponen tres ejemplares auténticos, que se sitúan en la mesa de la presidencia donde primeramente firmará el presidente de las Cortes Constituyentes, tras su firma estos ejemplares serán trasladaos a otra mesa situada en el centro del salón de sesiones, donde además, se dispuso un asiento para el Secretario de la Cortes y donde los diputados presentes, fueron firmando. El llamamiento se realizó por orden alfabético de provincias.

\footnotetext{
${ }^{2}$ Diario de Sesiones de las Cortes Constituyentes, núm. 88 de 2 de junio de 1869.
} 
Toda vez que fueron "pasadas las horas de Reglamento", se suspendió dicho acto para el día siguiente.

El 3 de junio se retoma el acto de firma de la Constitución en el mismo escenario y con el mismo procedimiento con el que se verificó el día anterior ${ }^{3}$, en este caso será el Vicepresidente de las Cortes quien dirá: “Continúa el acto de la firma de la Constitución del Estado", por tanto volverán a ser llamados a la firma los diputados restantes que quedaban por firmar, por orden alfabético de las provincias, tal como sucedió en la sesión del día anterior, concluyendo dicho acto solemne a las 17:30 horas, y tal como señala el Diario de Sesiones, expresando al respecto el Secretario de las Cortes: "Señor Presidente, está terminada la firma". Dándose por tanto fin a dicho acto que se verificó en dos días a tenor de lo establecido en el Reglamento en relación al horario de las sesiones.

\subsection{Decreto de 5 de junio de 1869}

Por decreto de las Cortes de 5 de junio de $1869^{4}$, por parte de la Presidencia del Poder Ejecutivo, se fija el día en el que tendrá lugar la promulgación de la Constitución. El decreto contiene tres artículos que de forma breve dispone que la solemne promulgación de la Constitución se realice en sesión extraordinaria de las Cortes Constituyentes, el día 6 de junio de 1869 (Artículo 19). En su artículo 2o se preceptúa que, una vez promulgada la Constitución los miembros ("Individuos" según el texto literal del Decreto) del Poder Ejecutivo "prestarán juramento acto continuo en manos del presidente de las Cortes". Y finaliza el articulado indicando que se remitirá al Poder Ejecutivo "uno de los originales de la Constitución firmado por los Sres. Diputados para que proceda inmediatamente a su promulgación en todos los pueblos de España: dictando al mismo tiempo las disposiciones oportunas para que tenga desde luego puntual cumplimiento en todas sus partes". Por tanto, a efectos protocolarios y relacionados con el ceremonial tenemos por una parte el acto formal de promulgación de la Ley Fundamental del Estado en el exterior de las Cortes Constituyentes, y el acto estricto de juramento de la mencionada Constitución en el interior de la sede parlamentaria.

\section{PÓRTICO DE LAS CORTES: ACTO DE PROMULGACIÓN DE LA CONSTITUCIÓN.}

Con carácter previo al mencionado Decreto, en la Gaceta de Madrid de 5 de junio de 1869, en "Anuncios Oficiales. Cortes Constituyentes" firmado por el Mayor de las Cortes Antonio de Castro y Hoyo, se comunicaba a los comisionados de las Diputaciones Provinciales y Ayuntamientos que "para asistir al acto solemne de promulgar la Constitución", que podían recoger en el Archivo de las Cortes "las esquelas de invitación" al mencionado acto. En relación a esta invitación, el Archivo del Congreso de los Diputados ${ }^{5}$ contiene el "Expediente de promulgación de la Constitución de 1869", donde aparece de

\footnotetext{
${ }^{3}$ Diario de Sesiones de las Cortes Constituyentes, núm. 89 de 3 de junio de 1869.

${ }^{4}$ Gaceta de Madrid, núm. 158 de 7 de junio de 1869.

${ }^{5}$ Unidad documental Compleja. A-02-000021-0018-001. Gobierno Interior. Legajo 21, ำ 18
} 
forma manuscrita la denominada "Lista en limpio", donde aparece la relación nominal de los comisionados para estar presentes en el acto de promulgación, pertenecientes a las Diputaciones Provinciales y Ayuntamientos invitados. El documento titulado en el encabezado como "Esquelas de invitación para el acto de promulgación de la constitución, repartidos a los Sres. Comisionados de provincias", detalla de forma clara la Provincia a la que pertenece, los nombres de los comisionados y la representación, ya sea Diputación Provincial o Ayuntamiento. También se encuentran comisionados de los denominados "Voluntarios de la Libertad", listado que supera los quinientos asistentes.

El mencionado expediente contiene también algunas de las "credenciales" ${ }^{6}$ remitidas por los Ayuntamientos y Diputaciones provinciales para asistir al acto de promulgación y donde nombran a sus comisionados, aparece el Ayuntamiento Constitucional de Laguna de Duero, la Diputación Provincial de Lugo,, el Ayuntamiento Constitucional de Cáceres, la Diputación Provincial de Zaragoza, la de Jaén y de Málaga. El expediente continúa ${ }^{7}$ con las credenciales de la Diputación Provincial de Cádiz, una nueva credencial de la Diputación Provincial de Jaén, la correspondiente al Ayuntamiento Constitucional de Tudela, del Gobierno de la Provincia de Sevilla, del Ayuntamiento Constitucional de San Fernando, el correspondiente de la "Villa de Bilbao, y por ultimo del Ayuntamiento Constitucional de Baeza.

El expediente conservado en el Archivo del contiene ${ }^{8}$ además el ofrecimiento para la instalación de luz eléctrica para iluminar la fachada del Palacio del Congreso con motivo del acto de promulgación de la Constitución, el ofrecimiento lo hace el Sr. J. Laurent en carta dirigida a las Cortes Constituyentes el 31 de mayo de 1869. Pero tal como aparece reflejado en el expediente, se señala que al final: "se puso iluminación de gas, y en la tribuna faroles a la veneciana".

Así pues, el domingo 6 de junio se produce la sesión extraordinaria para la solemne promulgación de la Constitución, dicho acto se desarrollará en el pórtico del palacio de las Cortes, mientras que el juramento tendrá lugar, una vez promulgada la misma, en el interior de las Cortes. Tal como recoge el Diario de Sesiones de las Cortes Constituyentes", "las Cortes pasan en corporación al pórtico del palacio". El Diario relata de forma clara cómo se desarrolló el mencionado acto, indicando la situación, colocación y precedencia de los asistentes a la promulgación, así a la salida del Presidente de las Cortes D. Nicolás María Rivero, precedido por los maceros, le siguieron inmediatamente los Sres. Secretarios y Diputados. Para el acto en el pórtico se instaló una tribuna, en cuyo centro se situó la mesa presidencial, donde tomó asiento el Sr. Presidente de las Cortes junto a los Secretarios (Llanos y Pérai, Sánchez Ruano y Carratalá).

\footnotetext{
${ }^{6}$ Unidad documental Compleja. A-02-000021-0018-0002-001. Gobierno Interior. Legajo 21, no 18.

${ }^{7}$ Unidad documental Compleja. A-02-000021-0018-0002-002. Gobierno Interior. Legajo 21, no 18.

${ }^{8}$ Unidad documental Compleja. A-02-000021-0018-0003. Gobierno Interior. Legajo 21, no 18

${ }^{9}$ Diario de Sesiones de las Cortes Constituyentes, núm. 92 de 6 de junio de 1869.
} 
El Poder Ejecutivo ocupó las primeras sillas a la derecha de la mesa presidencial, mientras que las situadas a la izquierda fueron ocupadas por la comisión de la Constitución, y las restantes por los Diputados presentes. Tal como señala el Diario de Sesiones "en ambas alas de la tribuna tomaron asiento: el Cuerpo Diplomático, el Consejo de Estado, el Tribunal Supremo de Justicia, la Audiencia, las Corporaciones militares, científicas y literarias, la Diputación Provincial y Ayuntamiento de Madrid, y las Comisiones y representantes de las Diputaciones, Ayuntamientos y milicia ciudadana de toda la Península".

La secuencia del acto fue el siguiente; el Secretario Llanos y Pérai solicitando la venia del presidente de las Cortes se "adelantó al frente de la tribuna" y en dirección a la plaza y al público asistente inició la lectura de una parte de la Constitución, siendo sustituido para finalizar la lectura de la parte restante por el Secretario Carratalá. Finalizada la lectura, Don Nicolás María Rivero declaró: "Como presidente de las Cortes Constituyentes, declaro en su nombre solemnemente promulgada la Constitución Democrática de 1869".

\section{SEDE DE LAS CORTES: ACTO DE JURAMENTO POR EL PODER EJECUTIVO DE LA LEY FUNDAMENTAL.}

\subsection{Fórmula de Juramento}

La fórmula de juramento establecida será la siguiente: “¿Juráis guardar y hacer guardar la Constitución democrática de la monarquía española? ¿Juráis haberos bien y fielmente en el encargo que la nación os ha encomendado, mirando en todo por el bien de la misma Nación?

\subsection{Juramento del Presidente del Poder Ejecutivo}

Concluido el acto de promulgación, se vuelve al interior de las Cortes donde se procederá a realizar el juramento de la Constitución por parte del Poder Ejecutivo. Así pues, estando todos los Diputados en sus asientos, el Presidente de las Cortes anunciará la toma de juramento, por lo que los Ministros, abandonando sus asientos y puestos en pie los Diputados "y todos los circunstantes", D. Francisco Serrano, Presidente del Poder Ejecutivo, se dirige hacia la mesa presidencial "y doblando la rodilla" presta juramento utilizando la fórmula anteriormente descrita, siendo el Secretario de las Cortes quien la formule, dando por respuesta "Sí juro", para seguidamente el presidente de las Cortes contestar al juramento con la fórmula: "Si así lo hiciereis, Dios y la patria os lo premien: y si no, os lo demanden".

\subsection{Juramento de los Ministros}

Verificado el juramento por parte del Duque de la Torre, Presidente del Poder Ejecutivo, serán los Ministros quienes con el mismo procedimiento, fórmula de juramento y sucesivamente en el siguiente orden: "Ministro de la Guerra, Marina e interino de Ultramar, Estado, Gracia y Justicia, Hacienda, Gobernación y Fomento", realizarán la jura a la norma fundamental. Con dicho acto por parte de los Ministros, se levanta la sesión extraordinaria, 
pasando los presentes a "presenciar el desfile de la fuerza armada", por lo que volverán a la tribuna dispuesta en el pórtico del Palacio de las Cortes.

\section{LOS ACTOS DE PROMULGACIÓN EN DISTINTAS CIUDADES DEL TERRITORIO NACIONAL}

El acto de promulgación se llevará a cabo en las capitales de provincia, también el día 6 de junio de 1869, siendo comunicadas por los respectivos Gobernadores al Ministro de Gobernación por despacho telegráfico ${ }^{10}$, e informando también de los mismos la prensa ${ }^{11}$ de ese momento histórico. Los numerosos despachos telegráficos hablan de distintos actos desarrollados en las mencionadas capitales, con presencia de todo tipo de autoridades y siempre con la ciudadanía presente, en otros supuestos relatados, como en Alicante el acto formal, se acompañará por una "parada dispuesta por las Autoridades militares para dar solemnidad al acto", al igual que en Sevilla. En casi todos los despachos telegráficos, se hace referencia a la solemnidad del acto, además de indicar con detalle las autoridades y corporaciones presentes, así el gobernador de Granada detalla que la norma fundamental se va a leer en tres ocasiones una en el "balcón de las casas capitulares", y las siguientes en "el balcón de la Audiencia y en el de la antigua Casa Consistorial", para finalizar en la Catedral con un "Te Deum". Por tanto el ceremonial no va a tener un carácter uniforme, en cada provincia se llevará a cabo de distinta manera, pero siempre con un acto central, tal como lo es la lectura de la carta magna.

Otros gobernadores serán muy escuetos en el telegrama como por ejemplo el de Lugo, que expondrá: "Se ha promulgado solemnemente la Constitución Entusiasmo indescriptible en el pueblo". En definitiva de forma simultánea en el mismo día se van a desarrollar en las capitales de provincias actos de promulgación que una vez finalizados serán informados al Ministerio de Gobernación, en todos el ceremonial se inicia con la lectura de la norma fundamental, pero variando la continuación del acto respecto de cada una de las localidades. La regla general es la de realizarla con la ciudadanía presente y asistencia de autoridades civiles, militares, corporaciones e incluso el cuerpo consular, algunas con desfile o parada militar, en otras con otro tipo de eventos de carácter festivo. Los telegramas incluso llegan a mencionar cuestiones de orden público, así el gobernador de Zamora informa de la siguiente manera: "Tranquilidad completa en la capital y provincia. Celebrada la promulgación de la Constitución con el mayor orden", por el contrario en otros supuestos se advierte de la inasistencia de la "autoridad eclesiástica", como señala el gobernador de Ávila; "El Obispo y Cabildo no han concurrido á pesar de estar invitados". Por tanto una ceremonia promulgación que tendrá su traslación al resto del territorio nacional respecto al celebrado en Madrid en el Palacio de las Cortes.

\footnotetext{
${ }^{10}$ Gaceta de Madrid, núm. 158 de 7 de junio de 1869.

${ }^{11}$ La Correspondencia de España, Diario Universal de Noticias. Año XX, núm.4216.
} 


\section{EL JURAMENTO DE LA CONSTITUCIÓN POR EL REGENTE}

Con el correspondiente nombramiento del Regente, producido el 17 de junio de 1869, se va a establecer el ceremonial para llevar a cabo el acto de juramento de la Constitución por el mismo. Así por Decreto de 17 de junio de $1869^{12}$, se van a desarrollar, en seis artículos, el ceremonial y demás aspectos que caracterizaran a dicho acto. Para la toma del juramento se reunirán las Cortes Constituyentes en sesión extraordinaria, el día 18 de junio, en el salón de sesiones a las 14:00 horas, el decreto especifica de manera expresa que la asistencia tanto del Poder Ejecutivo como de los Diputados se realizará "en traje de ceremonia".

El ceremonial se iniciará con la lectura del nombramiento del Regente, para que a continuación los Diputados nombrados reglamentariamente (15 diputados) salgan a recibir al Regente, el cual llegado a las Cortes y acompañado por los Diputados que lo han recibido, se dirigirá al Salón de Plenos, donde los presentes "se pondrán en pié, permaneciendo sentado el Presidente". Llegado al Salón se situará en el lado derecho de donde se encuentra sentado el Presidente de las Cortes Constituyentes, el cual utilizará la siguiente fórmula de juramento para que la verifique el Regente: “¿Juráis guardar y hacer guardar la Constitución de la Nación española de 1869 y las leyes del país, no mirando en cuanto hiciereis sino al bien y á la libertad de la patria?" El Regente responderá en voz alta: "Sí juro; y si en lo que he jurado, ó parte de ello lo contrario hiciere, no debo ser obedecido; antes aquello en que contraviniere sea nulo y de ningún valor", contestando Presidente de las Cortes: "Si así lo hiciereis, Dios y la patria os lo premien, y si no os lo demanden". A continuación tomará asiento a la derecha del Presidente, una vez hecho lo harán el resto de diputados presentes en el salón de sesiones.

El acto continuará tomando la palabra el presidente de las Cortes pronunciando una breve alocución poniendo fin al acto: "Las Cortes Constituyentes han presenciado y oído el juramento que el Regente acaba de prestar á la Constitución de la Nación española y á las leyes del país". Terminada la misma el Regente acompañado por los mismos quince diputados que le acompañaron a la entrada abandonará el Palacio de las Cortes.

\section{LOS MINISTERIOS Y EL JURAMENTO DE LA NORMA FUNDAMENTAL DE 1869.}

\subsection{Ministerio de Gracia y Justicia}

\subsubsection{Decreto de 9 de junio de 1969}

Transcurridos varios días desde la promulgación de la norma fundamental de 1869, el Ministerio de Gracia y Justicia, decreta con fecha de nueve de junio de $1869^{13}$, por mandato del Poder Ejecutivo, las fechas para proceder a los actos de juramento de los Tribunales y

\footnotetext{
${ }^{12}$ Gaceta de Madrid, núm. 169 de 18 de junio de 1869.

${ }^{13}$ Gaceta de Madrid, núm. 161 de 10 de junio de 1869.
} 
Juzgados, así como la fórmula de juramento, aspectos que iremos desglosando en los siguientes subapartados, y diversos supuestos específicos respecto a lo decretado. En relación con los supuestos específicos, señalar que el artículo 5 dispone los supuestos en los que, por enfermedad, ausencia "u otra causa legítima" no puedan llevar a cabo el juramento en "el día en que lo verifique la corporación á que correspondan", podrán llevar a cabo dicho juramento "en particular antes de volver a entrar en el ejercicio de sus funciones", se trata por tanto de un precepto de carácter general para dichos supuestos. En relación con las "Audiencias de Mallorca y Canarias, el artículo 7 establece que se verificará el juramento de dichas Audiencias "el primer día festivo inmediato" a la recepción del Decreto que estamos analizando.

Con carácter general y en relación al procedimiento, el artículo 6 dispone un plazo de ocho días desde la verificación de los juramentos, en el cual tanto el presidente del "Tribunal Supremo de Justicia" como los "Regentes de las Audiencias" deberán remitir al Ministerio de Gracia y Justicia la "correspondiente certificación del acta de la ceremonia, y los Jueces de primera instancia lo verificarán igualmente por conducto de los respectivos Regentes" de las distintas Audiencias.

\subsubsection{Fórmula de Juramento}

El artículo 4 del mencionado decreto dispone la fórmula de juramento, señalando que la misma será la siguiente: “¿Juráis guardar y hacer guardar la Constitución de la Monarquía española? ¿Juráis haberos bien y fielmente en el cargo que la Nación os ha encomendado, mirando en todo por el bien de la misma?", debiendo contestar "Sí juro", y continuando la fórmula de la siguiente manera "Si así lo hiciereis, Dios y la patria os lo premien; y si no os lo demanden, además de exigiros la responsabilidad con arreglo a las leyes".

\subsubsection{Tribunal Supremo de Justicia y la Audiencia de Madrid}

Por disposición del artículo 1 del Decreto de 9 de junio de 1869, el 13 de junio de se llevará a cabo, ante el ministro de Gracia y Justicia, Antonio Romero Ortiz, el acto de juramento a la Constitución por parte del Presidente, Presidentes de Sala, Fiscal y Ministros del Tribunal Supremo, así como también por el Regente de la Audiencia de Madrid. Una vez verificados estos juramentos, y en el mismo acto, seguidamente el "Teniente Fiscal, Abogados Fiscales, Secretario, Vicesecretario, Relatores, Secretarios-Relatores, Escribanos de Cámara y subalternos" del Tribunal Supremo, prestarán el correspondiente juramento ante su Presidente. Por lo tanto, se puede apreciar que se desarrollan dos actos de verificación en relación ante quien se lleva a cabo el mismo, por una parte, ante el Ministro de Gracia y Justicia y una vez jurada la Constitución por parte del Presidente del Tribunal Supremo, el resto de miembros que componen la estructura y personal del Tribunal, ante él. 
Por medio de un "Anuncio Oficial" de la Secretaría de Gobierno del Tribunal Supremo de 25 de junio de $1869^{14}$, el presidente del Tribunal Supremo, de "conformidad a lo prevenido por S.A. el Regente del Reino en decreto de 22 del mes actual, inserto en la GACETA del 23", viene a establecer el señalamiento de fecha y hora para la verificación del correspondiente juramento a la Constitución por parte de "los Tenientes y Abogados fiscales, Secretarios y Vicesecretarios, y demás empleados y dependientes que hayan sido de este Supremo Tribunal o del de Órdenes militares que residen en esta capital y se encuentren en la clase de cesante o jubilado", señalándose como fecha el 4 de julio de 1869 a las doce y media. Llevándose a cabo el juramento ante el presidente de dicho Tribunal.

Continúa el Anuncio estableciendo una serie de advertencias y anuncios, señalando que: "Lo que de su superior orden se avisa a los interesados por este solo anuncio: previniéndoles que con 48 horas de anticipación a la antes marcada remitan a esta secretaría de gobierno de mi cargo nota expresiva de su nombre y apellido, cargo que han desempeñado, situación de jubilado o cesante en que se encuentren y señas de su domicilio en esta capital, para que surta sus efectos en el expediente de referencia". Por tanto, se establecen unos requisitos previos para que estos empleados en situación de jubilado o cesante puedan asistir al acto de juramento y llevarlo a cabo, para así surtan los efectos correspondientes en relación con su situación.

En el mismo sentido y en relación a la Audiencia de Madrid, por una Orden de 29 de junio de $1869^{15}$, viene a disponer que toda vez que no se ha realizado mención especial en la Orden de la Regencia del Reino del 22 de junio de $1869^{16}$, en relación a los Presidentes de Sala, Fiscales y Magistrados cesantes o jubilados de la Audiencia de Madrid, respecto a aquellos funcionarios, "empleados pasivos" que debían prestar juramento a la norma fundamental, aseverando la orden "aun cuando aquellos se hallan virtualmente comprendidos en las mismas", se establece que dichos cesantes y jubilados de la Audiencia de Madrid que residan en Madrid verifiquen el juramento el 4 de julio, debiendo prestar el mismo ante el Regente de la mencionada Audiencia. $Y$ debiendo realizarse la misma conforme a lo preceptuado en la Orden de 22 de junio de 1869 en relación con la forma de juramento y "demás extremos que abraza".

Por otra parte, esta Orden de 29 de junio, establece que queden "implícitamente comprendidos" en la misma "aquellos individuos o dependientes del extinguido Tribunal de Cruzada", y que residan en Madrid, verificando el juramento el 4 de julio también ante el Regente de la Audiencia de Madrid. Tanto para uno como para otros que no residan en Madrid, la Orden dispone que se esté a lo establecido en los artículos 4 al 9 de la Orden de 22 de junio, tanto para los que residan fuera de Madrid y dentro de la Península Ibérica, como para los residentes en Baleares y Canarias y residentes en el extranjero.

\footnotetext{
${ }^{14}$ Gaceta de Madrid, núm. 178 de 27 de junio de 1869.

${ }^{15}$ Gaceta de Madrid, núm. 181 de 30 de junio de 1869.

${ }^{16}$ Gaceta de Madrid, núm. 174 de 23 de junio de 1869.
} 


\subsubsection{Tribunales y Juzgados}

Respecto a las Audiencias de la Península, el artículo 2 del Decreto que estamos analizando, establece que el día 20 de junio de 1869 se llevará a efecto el correspondiente juramento, "debiendo prestarlo los Regentes ante el Presidente de Sala más antiguo, y ante el Regente los Presidentes de Sala, Fiscal, Abogados Fiscales, Jueces de primera instancia que residan en el mismo punto que la Audiencia, Registrador de la Propiedad, Jueces de paz y suplentes, Médicos forenses, Relatores, Escribanos de Cámara y de actuaciones, Notarios, Procuradores y subalternos del Tribunal", estableciéndose ese mismo día la verificación del juramento de la Constitución por parte de los Jueces de primera instancia de los demás Juzgados, ante el "respectivo Promotor fiscal; este, los Jueces de paz del partido, suplentes, Promotor fiscal sustituto, Registrador, Médico forense, Escribanos de actuaciones, Notarios, Procuradores y subalternos del Juzgado lo prestarán a seguida ante el Juez de primera instancia", en este caso estamos haciendo referencia a aquellos que no "residan en el mismo punto que la Audiencia". Así el artículo 3 concluye estableciendo que se prestará el juramento ante el "Juez decano de los de primera instancia", en aquellos supuestos donde no resida la Audiencia del Territorio o donde existan dos o más Juzgados.

\subsubsection{Orden reformando el Reglamento Orgánico del Notariado}

Ante la verificación por parte del Ministerio de Gracia y Justicia que tanto la fórmula de juramento como el acto solemne en el que se realizaba el juramento de los notarios, de acuerdo con lo establecido en el artículo 42 del Reglamento de 30 de diciembre de 1862, por una Orden de 7 de julio de 1869 , se establece una nueva redacción en relación a ese artículo, disponiendo un requisito previo en relación a la toma de toma de posesión, como es el de aportar previamente, o como señala la Orden "con la oportuna anticipación", su título a la Sala de gobierno correspondiente. Siendo esta Sala la que establecerá día y hora para que se preste el juramento en "audiencia pública", debiéndose presentar a dicho acto con dos Colegiados, tal como dispone el artículo 41 del señalado reglamento, seguidamente el presidente hará entrega al secretario del título, que pasará a dar lectura "en voz alta" y una vez concluida la lectura, se verificará el juramento diciendo el secretario "Procédase al Juramento", utilizándose para ello la siguiente fórmula: “¿Juráis guardar la Constitución de la Monarquía española y las leyes, y cumplir bien y lealmente las obligaciones de vuestro cargo?", debiendo contestar el notario electo "Sí juro" y continuando el secretario señalando "Si así lo hiciereis, Dios os lo premie; y si no os lo demande, además de vuestra responsabilidad con arreglo a las leyes".

Destacar que en relación con esta fórmula de juramento no se incluye referencia alguna a la patria, tal como sí incluye la fórmula establecida para el juramento de Tribunales y Juzgados "Si así lo hiciereis, Dios y la patria os lo premien; y si no os lo demanden, además de exigiros la responsabilidad con arreglo a las leyes", tal como hemos visto anteriormente. 


\subsection{Ministerio de Gobernación}

El Ministerio de Gobernación establecerá por medio de Decretos ${ }^{17}$ una serie de disposiciones relativas a la toma del juramento de la Constitución de 1869 , así el primero de los Decretos con fecha 17 de junio de 1869, establece que el día 21 de junio, deberán verificar el juramento ante el Ministro de Gobernación, los Ministros, los subsecretarios y directores generales cesantes de Gobernación que residan en Madrid, el lugar para llevará a cabo dicho acto será el despacho del Ministro de Gobernación a las once y media de la mañana. Para los supuestos de los funcionarios a los que hemos hecho referencia no residan en Madrid, la misma se verificará ante el "Gobernador o Alcalde Popular" del lugar en que residan o se encuentren.

Con carácter general se va a señalar el procedimiento a seguir para aquellos "funcionarios activos, cesantes y jubilados que residan en el extranjero", se entiende que sean dependientes del Ministerio de Gobernación, para que verifiquen el juramento ante los Representantes de España en el lugar donde residan o se encuentren. En los países en los que España no tenga representación deberán prestarla "de oficio" remitiéndola por escrito "en el término de un mes" al "centro administrativo de quien hubieren recibido el nombramiento de mayor categoría".

El segundo Decreto, con igual fecha que el primero, va a establecer la fórmula de juramento y el procedimiento para llevarlo a cabo con carácter general. La fórmula de juramento utilizada será la siguiente: “¿Juráis guardar y hacer guardar la Constitución española promulgada en 6 de junio de este año? ¿Juráis haberos bien y fielmente en los deberes que como funcionario y como ciudadano tenéis contraídos, mirando en todo por el bien de la Nación?", debiendo contestar "Sí juro", siguiendo la fórmula de la siguiente manera: "Si así lo hiciereis, Dios y la patria os lo premien; y si no os lo demanden, además de exigiros la responsabilidad con arreglo a las leyes".

A su vez viene a establecer que el mismo se llevará a cabo "en un mismo día en todos los pueblos de cada provincia", siendo potestad de los Gobernadores establecer la fecha correspondiente, debiendo a su vez publicar el Decreto en los "Boletines Oficiales". (Apartado 7ㅇ). Al igual que en el resto de disposiciones de distinto ámbito e institución es preceptivo el correspondiente certificado o acta de verificación del juramento, donde conste el mismo.

El Decreto continúa disponiendo el procedimiento necesario para que se guarden todas las formalidades y solemnidades en distintos ámbitos, así se hace una pormenorizada secuencia de autoridades que han de prestar el juramento, la forma y ante quién deben de llevarla a cabo, así como otras formalidades tendentes a la correcta y conveniente verificación de la jura. Así los gobernadores de provincias harán el juramento ante el Secretario de su respectiva sede. Una vez verificado el mismos serán los gobernadores quien

\footnotetext{
${ }^{17}$ Gaceta de Madrid, núm. 169 de 18 de junio de 1869.
} 
tomarán juramento al "Secretario del Gobierno, Secretario del Gobierno, del Vicepresidente de la Diputación provincial, del Alcalde primero popular de la capital de su provincia, de todos los empleados activos, cesantes y jubilados dependientes de este Ministerio que residan en ella".

Será el Vicepresidente de cada Diputación provincial quien verificará el juramento a los "individuos todos que la componen", por tanto, a todos los funcionarios dependientes de dicha institución. Por lo que respecta a los Alcaldes, se establece un doble procedimiento según sean alcaldes de capitales o alcaldes primeros populares, los alcaldes de capitales deberán seguir el mismo procedimiento que se establece en el apartado segundo, es decir ante el Gobernador de su provincia. Los Alcalde populares verificarán el juramento ante el "segundo alcalde" y en caso que se carezca del mismo ante el "Regidor primero". Una vez verificado el juramento del alcalde, este lo recibirá del segundo alcalde o Regidor, quienes a su vez tomarán juramento a todos los miembros y funcionarios dependientes del Ayuntamiento. Dicha competencia a los Alcaldes se extiende a los "dependientes" del Ministerio de Gobernación que residan en dicho municipio, incluyendo también a los cesantes y jubilados. Por último, también verificarán el juramento de los denominados "Jefes de las fuerzas ciudadanas".

El Decreto finaliza con el establecimiento de un plazo para poder llevar a cabo el juramento, consecuencia, tal como lo expresa el apartado 8o; "Como causas que no es fácil prever pudieran impedir a algunos de los que han de prestar el juramento hacerlo en el día que se designe", por este motivo los Gobernadores concederán un plazo de 15 días adicionales para que puedan llevar a cabo el juramento de la norma fundamental con el procedimiento y formalidades establecidas.

\subsection{Ministerio de Hacienda}

El Ministerio de Hacienda establecerá disposiciones relacionadas con el juramento que sus funcionarios, órganos e instituciones deberán de llevar a cabo preceptivamente. El proceso se inicia en junio de 1869 para terminar finalmente en agosto de 1870. La primera disposición que publicará el Ministerio de Hacienda tiene fecha de 16 de junio de $1869^{18}$ donde se va a disponer la forma de juramento por parte de los funcionarios activos, para ello se va a disponer como fecha de verificación del acto de juramento el 19 de junio de 1869 estableciéndose como lugares del acto en Madrid, el "Tribunal de Cuentas del Reino, en la Secretaría del Ministerio y en las Direcciones generales y oficinas centrales". El Ministro de Hacienda será quien recibirá el juramento a los miembros del Tribunal de Cuentas, los cuales verificado su juramento lo tomarán al resto de funcionarios "de las oficinas centrales".

Se establece como fórmula de juramento la siguiente: “¿juráis guardar y hacer guardar la Constitución española, promulgada en 6 de Junio de este año; juráis haberos bien y fiel-, mente en los deberes que como funcionario y cómo ciudadano tenéis contraídos,

\footnotetext{
${ }^{18}$ Gaceta de Madrid, núm. 169 de 16 de junio de 1869.
} 
mirando en todo por el bien de la Nación?" debiendo contestar "Sí juro", continuando diciendo: "Si así lo hiciereis, Dios y la patria os lo premien; y si no os lo demanden, además de exigiros la responsabilidad con arreglo a las leyes".

Se dispone que respecto a la jura de los "ex-Ministros y Jefes superiores de Administración, y ante los Directores respectivos los Jefes de Administración" se establecerá para dicho acto una fecha determinada. Así como que aquellos que se encuentren ausentes, enfermos o los que por cualquier otra "causa legítima" no puedan verificar el juramento en el marco establecido "lo prestarán en particular antes de volver a entrar en el ejercicio de sus funciones". Por su parte los funcionarios dependientes del Ministerio de Hacienda ya se encuentren activos, cesantes o jubilados que se encuentren en "las provincias" lo verificarán ante el Gobernador si residen en la capital de la Provincia, caso que no sea así, lo llevarán a cabo ante el Alcalde donde residan.

Con fecha 26 de junio de $1869^{19}$, se publica una Orden que va a establecer el procedimiento de jura de cesantes y jubilados del Ministerio que "perciben sus haberes por la Tesorería Central", puntualizando que distintos Ministerios ya han dispuesto al respecto, debiendo "acordar lo conveniente en cuanto a los que se hallan en esta capital o fuera de la Península y tienen consignado su haber pasivo sobre la Tesorería Central". Así pues ante el Ministro de Haciendo deberán jurar la constitución "los ex-Ministros de Hacienda y Jefes superiores de Administración de la misma, cesantes ó jubilados que se encuentren en esta capital", y estableciéndose como fecha de verificación del acto el 19 de junio a las 13:00 horas y como lugar el despacho del Ministro de Hacienda. En esa misma fecha y horario ante el Director general del Tesoro público lo prestarán los "Jefes de Administración de Hacienda" y ante el "Ordenador general de Pagos de Clases pasivas, y ante el funcionario más caracterizado del Cuerpo diplomático o consular español de la respectiva localidad, y en el plazo de un mes los que perteneciendo a cualquiera de las tres clases indicadas residan en el extranjero".

Cuando no se cuente con Representación, los funcionarios que se encuentren enfermos o ausentes de "la Península", podrán llevar el juramento en el plazo establecido, utilizando la vía de "oficio dirigido" al Ministerio de Hacienda, junto al justificante correspondiente de no poder hacerlo en tiempo y forma.

Habiendo prestado juramento los funcionarios dependientes de la Vicepresidencia de la Junta General de Estadística conforma a lo dispuesto anteriormente, la misma establecerá con fecha 22 de junio de $1869^{20}$ el procedimiento para que verifiquen el juramento a la norma fundamental "los Oficiales y Auxiliares las Secciones provinciales de Estadística y los cesantes y jubilados que residan en la capital", lleven a cabo la misma ante los Gobernadores, y los que residan fueran de la capital ante el Alcalde que le corresponda. La disposición establece la fórmula por la cual se llevará a cabo:"¿Juráis guardar y hacer

\footnotetext{
${ }^{19}$ Gaceta de Madrid, núm. 179 de 28 de junio de 1869.

${ }^{20}$ Gaceta de Madrid, núm. 184 de 3 de julio de 1869.
} 
guardar la Constitución de la Monarquía española? ¿Juráis haberos bien y fielmente en el cargo que la Nación os ha encomendado, mirando en todo por el bien de la misma?". Debiendo contestar "Sí Juro", continuándose con la fórmula de juramento de la forma siguiente: "Si así lo hiciereis, Dios y la patria os lo premien; y si no os lo demanden, además de exigiros la responsabilidad con arreglo a las leyes".

Para los supuestos de enfermedad, ausencia o cualquier otra causa justificada el juramento lo podrán prestar "en particular al entrar de nuevo en el ejercicio de sus funciones".

En el mes de diciembre de 1869 tendrá lugar la publicación de la Ley ${ }^{21}$ por la cual aquellos que no hayan jurado o no acrediten haber verificado el juramento en el "término de un mes y ante las autoridades competentes", de forma expresa se declara "sin derecho a desempeñar destinos y funciones públicas y al percibo de haberes de retiro cesantía y jubilación".

La Contaduría General de la Hacienda Pública resultado de la Orden de la Dirección General del Tesoro Público, de 28 de diciembre de 1869, realizará una advertencia en relación a los funcionarios cesantes, jubilados y "retirados" que "tienen consignado el pago de sus haberes en la Tesorería Central de Hacienda pública" y consecuencia de las distintas disposiciones publicadas, que en debido cumplimiento a lo mandado en la ley", la ley a la que hace referencia es de 18 de diciembre de 1869 y que podremos ver brevemente en un apartado posterior, "serán dados de baja en la nómina de enero próximo todos los interesados que no justifiquen haber prestado juramento a la Constitución ante las Autoridades competentes dentro del término señalado en la citada ley". Por tanto no verificándose le juramento en el plazo establecido, dichos haberes dejarán de ser pagados en el mes de enero de 1870.

Ya iniciado el mes de enero de 1870, por medio de un Anuncio Oficial ${ }^{22}$ vía Subsecretario del Ministerio de Hacienda, se dispone la fecha del 13 de enero de 1870 a las 12:00 horas en el despacho del Ministro de Hacienda, para que puedan verificar el juramento a la norma fundamental los "ex Ministros y Jefes Superiores de Hacienda, cesantes o jubilados" tal como previene la Ley de 18 de diciembre de 1869. Además dispone también la posibilidad de que puedan llevarlo a cabo también, en la misma fecha y hora, pero en este supuesto ante el Director General del Tesoro Público "los jefes de Administración de Hacienda que se encuentren también en situación pasiva".

Para finalizar señalar que en el mes de agosto aparecerá publicada la última norma en relación al juramento procedente a los empleados dependientes del Ministerio de Hacienda, se trata de una Circular $^{23}$ donde consecuencia de unas consultas realizadas sobre

\footnotetext{
${ }^{21}$ Gaceta de Madrid, núm. 353 de 19 de diciembre de 1869.

${ }^{22}$ Gaceta de Madrid, núm. 11 de 11 de enero de 1869.

${ }^{23}$ Gaceta de Madrid, núm. 215 de 3 de agosto de 1870.
} 
la exigencia o no de que verifique juramento de la Constitución por parte de los "exclaustrados", y siendo que el Ministerio de Gracia a Justicia ha establecido la obligación de prestar juramento, se ordena por parte del Ministro de Hacienda al Director General del Tesoro Público la inserción de un Anuncio Oficial en el Boletín Oficial de la Provincia, donde se anuncie dicha obligación a los exclaustrales, y tal como dice la circular "si han de seguir cobrando sus haberes". Disponiendo un plazo de un mes para que la verifiquen, advirtiendo que transcurrido dicho plazo "serán dados de baja en sus nóminas". Como se deduce de lo expuesto se trata de una consecuencia más de la Ley de 18 de diciembre de 1869.

\subsection{Ministerio de Ultramar}

Por parte de este Ministerio se hace uso también de un Decreto con fecha 17 de junio de $1869^{24}$ para disponer la forma en que ha de realizarse la jura de la norma fundamental por parte de los funcionarios públicos, activos y cesantes del referido Ministerio. El Decreto lo conforman once disposiciones que vienen a desglosar todo el procedimiento de juramento y especificidades en relación a dichos empleados públicos, procedimiento muy similar al del resto de Ministerios y que también son decretados.

Así pues, con carácter previo para el inicio de este procedimiento escalonado, el Ministro de Ultramar tomará juramento al Subsecretario y éste a su vez a los Jefes de Sección del Ministerio, "y aquel a los demás funcionarios del mismo departamento". (1으)

Se señala como fecha para la toma en consideración del juramento, en relación a los empleados de la "Administración central" en Madrid el 22 de junio, estableciéndose la fecha de 26 de junio para los empleados del Archivo General de Indias en Sevilla (7으). En relación a las provincias de Ultramar sus "gobernadores superiores civiles" y respecto de Fernando Póo, tendrán la potestad de señalar el día que consideren para que se preste el referido juramento y tal como se dispone en el apartado 8o procurando "que el acto se celebre con toda solemnidad. Además de indicar la posibilidad de que se lleve a cabo "simultáneamente en todos los distritos de cada una de dichas provincias".

Así pues, el Regente de la Audiencia de la Habana y los de Puerto Rico y Filipinas "recibirán el juramento, con las solemnidades de costumbre", a los Gobernadores superiores civiles de dichas y respectivas provincias. Para que a continuación los referidos Gobernadores dispongan la forma en que deben de prestar juramento las "corporaciones y funcionarios" ya se encuentren en situación activa como pasiva, de las "provincias de su mando" ( 2 y 3 ㅇ). Respecto a Fernando Po será su Juez letrado y en su "defecto el Secretario de Gobierno" quien tome juramento de la Constitución al "Gobernador de aquellas provincias" (4ㅇ).

\footnotetext{
${ }^{24}$ Gaceta de Madrid, núm. 171 de 20 de junio de 1869.
} 
Por lo que respecta al Archivo de Indias, su encargado prestará juramento ante el Gobernador de la provincia de Sevilla, pasando seguidamente dicho encargado a recibir el juramento de los empleados del Archivo.

Como ocurre en otros procedimientos de igual naturaleza, también se establece el cauce parta la toma de juramento de cesantes, jubilados, enfermos o ausentes. Así respecto a los "ex - Ministros y Jefes superiores" llevarán a cabo el mismo ante el Ministro de Ultramar, siempre y cuando sean residentes en Madrid, para ello se dispondrá como fecha el 24 de junio de 1869. En esa misma fecha, posteriormente a la toma de juramento anteriormente señalada, se les tomará a los "demás empleados pasivos" cesantes y jubilados. En el supuesto que la residencia de los mismos se encuentre en el extranjero o en las provincias, prestarán el mismo en su lugar de residencia ante "los Alcaldes, Gobernadores o Representantes de España". Aquellos que residan fuera de España se añade la obligatoriedad de remitir por escrito y de "oficio" la prestación de juramento al Ministerio de Ultramar su juramento, disponiéndose el plazo de un mes para llevarlo a cabo. Por último y en consideración a los supuestos señalados, caso de que se resida allí donde no exista representantes de España "prestarán de oficio su adhesión a la norma fundamental en la forma que previene esta disposición". (Apartado 9). Para los que padezcan enfermedad, ausencia o como señala el Decreto en el apartado 10우 "o por otra causa legítima", sea imposible llevar a cabo el juramento de la Constitución en las fechas que se han dispuesto, "lo verificarán en particular en arreglo a la disposición anterior", establecida en el número 9․

Con carácter expreso se establece el deber de elevar al Ministerio de Ultramar, por parte de todas las autoridades que hemos referenciado, las actas correspondientes donde consta "el cumplimiento de las prescripciones de este decreto" además de la prerrogativa de tener que adjuntar a dichas actas la relación nominal de aquellos que hayan llevado a cabo el juramento, "firmadas por estos y con expresión de los destinos que ejerzan o hubieren ejercido", (Apartado 11으).

Finalizamos señalando que el Decreto también dispone la fórmula de juramento que se debe de llevar a cabo en estos supuestos que estamos analizando, la cual será la siguiente: “¿Juráis guardar y hacer guardar la Constitución española, promulgada en 6 de Junio de este año?; juráis haberos bien y fielmente en los deberes que como funcionario y como ciudadano tenéis contraídos, mirando en todo por el bien de la Nación?" Debiendo contestar "Sí juro" y continuando "Si así lo hiciereis, Dios y la patria os lo premien; y si no os lo demanden, además de exigiros la responsabilidad con arreglo a las leyes". La fórmula es similar a otras de las utilizadas por otras instituciones en su estructura, pero con pequeños cambios. 
Indicar que el señalamiento de día y hora para recibir el juramento por parte de los empleados pasivos vendrá reflejado por medio de un Anuncio Oficial ${ }^{25}$.

\subsection{Ministerio de Fomento}

En el Ministerio de Fomento también se van a concatenar distintas disposiciones en relación al juramento de la Constitución, así con fecha 17 de junio de $1869^{26}$ se formulan dos Decretos. El primero de ellos establece la fórmula de juramento dirigida a todos los funcionarios del Ministerio de Fomento, estableciendo cuatro apartados donde se establece el ceremonial y procedimiento para llevar a cabo el acto: Como en todas las disposiciones que sobre este particular se analiza en el presente estudio, se establece en primer lugar, la fecha, hora, lugar y quiénes deberán de verificar el juramento, así la fecha señalada será el 25 de junio a las diez de la mañana y en la sede del Ministerio entendiendo que se realiza en ese lugar al señalar la disposición que "prestarán el juramento en mi presencia" es decir ante el Ministro (Manuel Ruiz Zorrilla). Siendo convocados para este primer acto los "Directores y Oficiales" del Ministerio, "el Rector de la Universidad Central, los Directores de la Biblioteca Nacional, Museo Arqueológico, Institutos de segunda enseñanza y escuelas especiales". Seguidamente se establece el procedimiento de jura para el resto de empleados del Ministerio, que lo harán ante el "Jefe de Negociado Central".

En esa misma fecha y respecto a las provincias, los gobernadores de las mismas verificarán el juramento de los empleados dependientes del Ministerio en las mismas y "los Jefes de los Archivos y las Bibliotecas el de sus subordinados". Como es clausula de estilo en todos estos procedimientos se establece la obligatoriedad de certificar mediante acta el juramento y remitir al Ministerio del ramo.

La fórmula de juramento, similar a otras que veremos, contienen una serie de especificidades dado el carácter de a quienes va dirigido, es decir a funcionarios y la misma será la siguiente: “¿Juráis haberos bien y fielmente en los deberes que como funcionario y como ciudadano tenéis contraídos, mirando en todo por el bien de la Nación?" debiendo contestar "Sí juro", la autoridad que verifique el juramento continuará y dirá, "Si así lo hiciereis, Dios y la patria os lo premien; y si no os lo demanden, además de exigiros la responsabilidad en el ejercicio de vuestro cargo con arreglo á las leyes".

Por tanto, respecto de este primer Decreto destacamos que va dirigido a los funcionarios públicos activos, y será un segundo Decreto tal como ya hemos señalado quien dispondrá el acto solemne de juramento a los funcionaros públicos cesantes y jubilados del Ministerio. Tal como expresa de manera clara el encabezado de la disposición al señalar que "deseando que la jura de la Constitución de 1869 se lleve a efecto con toda solemnidad y a fin de evitar omisiones que, sobre poder ser torcidamente interpretadas, darían acaso lugar a que no prestasen el juramento todos los que tienen el deber de hacerlo", es por lo que se

\footnotetext{
${ }^{25}$ Gaceta de Madrid, núm. 173 de 22 de junio de 1869.

${ }^{26}$ Gaceta de Madrid, núm. 173 de 22 de junio de 1869.
} 
Decreta y se establece el procedimiento a seguir para que puedan verificar el juramento el día 26 de junio, a las diez de la mañana también y ante el Ministro, los "Ministros, Directores generales, Rectores y Oficiales de Secretaría" residentes en Madrid y con la condición de cesantes como funcionarios de dicho Ministerio.

Tal como ocurre en el primer Decreto ya analizado, el resto de empleados cesantes deberán verificar el juramento ante el Jefe de Negociado Central del Ministerio de Fomento. Ahora bien, lo que sí desarrolla el precepto son los supuestos de no residencia en Madrid, en cuyo caso lo harán ante el Gobernado de la Provincia o el Alcalde, en donde residan o se encuentren. Y para finalizar viene a disponer de manera expresa en el apartado 4 una regla de aplicación general a todos los funcionarios del Ministerio de Fomento, cesantes, jubilados o activos que se residan en el extranjero, al señalar que lo verificarán ante el Representante de España, y en lo que no exista esa representación deberán "prestarán de oficio su adhesión".

Desde el Negociado Central del Ministerio, utilizándose la vía de Anuncio Oficial ${ }^{27} \mathrm{con}^{2}$ fecha de 23 de junio de 1869, se va a realizar una enumeración exhaustiva de aquellos empleados del Ministerio que han de tomar "solemne juramento" de la Constitución, llevándolo a cabo ante sus respectivos "Jefes", el anuncio detalla y enumera a esos empleados: "empleados administrativos de la Universidad Central, Institutos del Noviciado y de San Isidro, Museo de Ciencias naturales, Escuela Normal, Colegio de Sordomudos y Ciegos, Escuelas especiales de Pintura, Escultura y Grabado; de Arquitectura, de Música y de Diplomática; Biblioteca Nacional, Museo Arqueológico, Escuela de Comercio y Conservatorio de Artes, Escuela de Veterinaria, Junta superior facultativa de Minas, de Montes, de Caminos, Canales y Puertos, y Escuelas de Ingenieros". Respecto de dichos empleados que no se encuentran en servicio activo el juramento se traslada al día 28 de junio a las once de la mañana y con el mismo procedimiento.

Se establece una advertencia con la que finaliza este Anuncio Oficial, que toda vez que respecto a estos empleados cesantes y jubilados se desconoce su residencia, se advierte que no se remitirá invitación formal y personal al acto, por lo que se señala como anuncio del mismo el Decreto al que ya hemos hecho alusión anteriormente.

No será ya hasta el año 1870, cuando el Ministerio, volverá a publicar nuevas disposiciones relativas al juramento de la Constitución, en relación a profesores, catedráticos, maestros y funcionarios de Instrucción Pública. El 23 de marzo de 1870 se dispone por parte del Ministerio de Fomento una $\operatorname{Orden}^{28}$ en la que se van a regular las situaciones de aquellos profesores de Instrucción pública que no hayan prestado juramento a la Constitución, o la hayan prestado en la forma no establecida. La Orden está dividida en ocho apartados. El primer apartado de la misma establece de inicio la separación "de sus

\footnotetext{
${ }^{27}$ Gaceta de Madrid, núm. 175 de 24 de junio de 1869.

${ }^{28}$ Gaceta de Madrid, núm. 95 de 5 de abril de 1870.
} 
cargos" a todos aquellos profesores "de todos los grados de la enseñanza oficial" que en relación al juramento de la norma fundamental se hayan negado a verificar la misma, teniendo efectos dicha separación desde el "1 de abril próximo". Por lo que se refiere a aquellos profesores que por distintas circunstancias no hayan realizado el juramento en la forma prevenida o "en distinta forma que la determinada en la Orden de 11 de enero último". Se vuelve a establecer una fecha determinada para que puedan a llevar a efecto el juramento en la forma prevenida, Caso que no lo hagan o reiteren hacerlo de forma distinta a la establecida, quedarán separados de sus cargos transcurrido el plazo de verificación, que es de ocho días desde la promulgación de la Orden que estamos analizando.

Aquellos profesores que aún estando en la Península, por el motivo que sea no hayan podido jurar la constitución, podrán llevar a cabo dicho acto en el término de ocho días desde la entrada en vigor de esta Orden, como dato significativo de este apartado está que la misma especifica que lo dispuesto afecta tanto los profesores civiles como los "eclesiásticos, toda vez que las funciones de estos como profesores públicos, sus derechos y deberes son iguales a los de los seglares". Caso de que no lleven a cabo lo estipulado quedarán al igual que en los demás casos separados de sus cargos y funciones.

Se extiende la aplicación de lo dispuesto en los apartados analizados a los "Auxiliares nombrados por los Claustros, Inspectores de primera enseñanza, Secretarios de las Juntas provinciales de este ramo y cuantos ejerzan funciones de la enseñanza oficial, cuya separación, en el caso de que proceda, se hará por las Autoridades a quienes corresponda su nombramiento, dando cuenta de ello" al Ministerio de Fomento.

Tomando como instrumento un Anuncio Oficial ${ }^{29}$ de 8 de abril de 1870, la Universidad de Madrid extiende la correspondiente invitación a aquellos Catedráticos en excedencia que no hayan verificado el correspondiente juramento o en su caso como establece el Anuncio lo hayan realizada en la forma no establecida al respecto, que la lleven a cabo en la forma prevenida ante el Rector de la Universidad de Madrid con un plazo de término para realizarla determinado, que en todo caso deberá ser antes del 13 de abril de 1870.

La última disposición de este Ministerio, al respecto, llevará la forma de Instrucción Pública $^{30}$, y data del mes de septiembre de 1870, en relación a distintas consultas realizadas respecto a la obligatoriedad de que los profesores nombrados después de haberse dictado las distintas disposiciones relativas al juramento de la Constitución, deban de verificar dicho juramento, disponiéndose en tal sentido, que los mismos, deberán acreditar haber prestado el juramento en la forma requerida y por las normas dispuestas en tal sentido, o hacerlo de forma expresa en el acto en el que tomen posesión de su cargo, con las formalidades establecidas al respecto.

\footnotetext{
${ }^{29}$ Gaceta de Madrid, núm. 100 de 10 de abril de 1870.

${ }^{30}$ Gaceta de Madrid, núm. de 6 de septiembre de 1870.
} 


\subsection{Ministerio de la Guerra}

Con una serie de disposiciones el Ministerio de la Guerra regulará el procedimiento y desarrollo por el que se regirá el juramento de las diferentes "armas e institutos del ejército", así por medio de una Circular general ${ }^{31}$, compuesta por doce apartados, viene a disponer carácter general, la fecha de 13 de junio de 1869 para verificar "en toda la Península la jura de la Constitución por todos los Generales, Jefes, Oficiales y soldados de las diferentes armas e institutos del Ejército", por tanto este primer apartado de la Circular ya establece una delimitación geográfica, circunscribiendo su área dispositiva a la Península Ibérica.

El segundo apartado establece distintos aspectos en relación al procedimiento, etiqueta, ceremonial, símbolos y honores con el que se caracterizará y desarrollará dicho acto. Así por parte de los "Capitanes generales, Gobernadores y Comandantes militares" deberá disponerse respecto de las "fuerzas de todas las armas e institutos que guarnezcan las capitales y puntos en donde se hallen", que formen en traje de gala, estableciendo libertad a la hora de establecer el orden que estimen más conveniente, "según las fuerzas que se reúnan", pero estableciendo una estructura de formación de las mismas de manera clara y expresa, así se dispone que se sitúe "al frente y en el centro de cada batallón de infantería y regimiento de caballería y de artillería de campaña, la bandera o estandarte con su escolta". Ante esta disposición de tropas deberá presentarse la "Autoridad militar superior", delante de cada cuerpo, "sucesivamente" como indica el apartado, para tomar juramento, siguiendo el ceremonial siguiente, deberá adelantarse el jefe del correspondiente cuerpo ante el que se presente dicha autoridad militar superior, debiendo "colocar su espada horizontalmente sobre el asta de la bandera o estandarte formando cruz", debiendo la tropa presentar armas, para seguidamente la autoridad militar pronunciar la fórmula de juramento. Finalizado el juramento, por una parte la "Autoridad colocará en las banderas y estandartes la insignia conmemorativa de la jura" y para finalizar el referido acto se llevará a cabo un desfile.

Para aquellas fuerzas y destacamentos que se encuentren "diseminadas del Ejército, Carabineros y Guardia Civil", los Capitanes generales deberán establecer la concentración de las mismas, en la forma que estimen conveniente, para que presten o verifique el juramento "ante un Jefe del respectivo cuerpo e instituto y con la solemnidad prevenida" (Apartado 40). Respecto a lo dispuesto a la solemnidad requerida, habrá que estar a lo señalado respecto al resto de miembros de la tripulación del buque en el apartado segundo.

En relación a los oficiales empleados, de cuartel y exentos de servicio, hace referencia el apartado 5 a Generales y Brigadieres, y los Jefes y Oficiales "sin mando de tropa y los de reemplazo" señalados en el apartado 7으, verificarán su juramento también el 13 de junio "ante el Capitán general o Autoridad militar del punto en que se encuentren", la autoridad

\footnotetext{
${ }^{31}$ Gaceta de Madrid, núm. 161 de 10 de junio de 1869.
} 
militar deberá realizar dicho acto en su "casa - habitación" previa convocatoria a la misma de dichos oficiales. Se establece que aquellos que se encuentren en el extranjero deberán llevar a cabo el juramento ante el Representante de España, con la obligación de informar fehacientemente haber verificado el mismo, al Ministerio de Ultramar, disponiendo para ello de un plazo de veinte días. Tratándose de Jefes y Oficiales "sin mando de tropa y los de reemplazo" que se encuentren en el extranjero con licencia realizarán la misma ante el Cónsul español "del punto en que se encuentren", ante la inexistencia del mismo, deberá hacerlo ante el cónsul "más inmediato". También aquellos Generales y Brigadieres residentes en Madrid así como las "tropas de su guarnición y cantones inmediatos" verificarán su juramento ante el Ministro de la Guerra (Apartado 9ㅇ).

Se establece una excepción respecto de los Capitanes generales y su juramento ante la correspondiente autoridad del lugar donde vivan, la misma se verificará, previa convocatoria, pero "con la separación de las demás clases militares" (Apartado 60). Para las Islas Canarias, el apartado 12 - señala que el juramento a la noma fundamental se lleve a cabo "esta solemnidad" en fecha distinta a la estipulada, esto es "el domingo inmediato al del día en que se reciba esta comunicación". En los casos que esta comunicación no llegue en tiempo suficiente, el juramento se prestará "el domingo inmediato al 20 de junio".

Debemos destacar que en esta Circular que estamos analizando no se hace referencia a los miembros del Ejército en Cuba, Puerto Rico, Filipinas y Fernando Poo, tal como sí dispone respecto al Ministerio de Ultramar.

Con carácter general se dispone que el 13 de junio el "pabellón nacional ondeará en todos los edificios militares" además se dispone que por la mañana, a medio día y a la puesta de sol, la artillería de las plazas llevarán a cabo tres salvas de 21 cañonazos (Apartado 10ㅇ).

Para finalizar señalar que la fórmula de juramento vendrá establecida en el apartado 2o y será la siguiente: "¿Juráis guardar y defender fiel y lealmente la Constitución de la Monarquía española, decretada y sancionada por las Cortes Constituyentes en 1869?" debiendo responder "Sí juramos", continuando a la autoridad correspondiente diciendo "Si así lo hiciereis, Dios y la patria os lo premien; y si no os lo demanden".

También hay que destacar que por medio de un Parte No Oficial de Interior, publicado en la Gaceta de Madrid $^{32}$ donde se informará y se dará cuenta del acto de juramento de la Constitución por las tropas de la guarnición y cantones inmediatos, tal como expresaba el apartado 2ㅇ de la Circular General anteriormente analizada, que se llevó a cabo en el Paseo de Atocha y el Prado, ante el General Prim que irá acompañado por el "Subsecretario, los Directores generales de las armas, batidores y escolta". Viene indicar ciertos datos interesantes en relación a la formación de las tropas "en regimientos" a los cuales el Ministro se acercaba y delante de "las banderas" verificaba el juramento establecido, en cada regimiento tras la jura se terminaba con un "viva la Constitución". Se

\footnotetext{
${ }^{32}$ Gaceta de Madrid, núm. 168 de 17 de junio de 1869.
} 
hace mención a la colocación de corbatas conmemorativas previstas para el acto, y que habían sido entregadas a los Jefes de los cuerpos, las mismas se entregarán al Ministro, que las irá colocando en las banderas presentes de cada regimiento. El acto finalizará con un gran desfile, el parte habla de la participación de "18.000 hombres", que desfilarán ante el General Prim y el Estado Mayor.

El 21 de junio se establecerá el correspondiente procedimiento de prestación de juramento por parte de los "Jefes y Oficiales" en este caso retirados, utilizándose como fórmula una Circular ${ }^{33}$, estructurada por seis apartados, en la que se dispone para ello un único acto de juramento, por una parte delegando a los "Capitanes Generales" la fijación de fecha y hora para el desarrollo del acto de verificación, pero estableciéndose con carácter expreso en la Circular que la misma deberá de tener lugar "en la casa-habitación de la Autoridad militar", además esa libre disposición para establecer día y hora para el acto viene acompañada por la expresada obligación tal como dispone el apartado 50, de que el juramento se desarrollará el mismo día "en todos los puntos de cada distrito militar". Como excepción se señala que en los supuestos en que dicha autoridad militar no exista, se llevará a cabo ante el Alcalde, estableciéndose aún así, la posibilidad de elección por parte de quienes deban prestar el juramento, de llevarlo a cabo ante la "Autoridad militar más inmediata", es decir la más cercana. El último apartado de la disposición vuelve a establecer como en otras disposiciones ya analizadas los supuestos de militares en situación de retiro que "accidentalmente" se encuentran residiendo fuera del país, repitiéndose el procedimiento como en otros casos en relación a otros funcionarios retirados, esto es presentación ante el representante o cónsul de España en donde residan, la circular habla de donde "se encuentren" y caso de no existir pues del más cercano. Con la expresa obligación de tener que remitir al "Capitán General del distrito donde tenga fijada su residencia en la Península en el término de 20 días", la correspondiente certificación de haber verificado el juramento a la Constitución, señalar que respecto a esto último la disposición ya advierte que estamos ante supuestos de residencia accidental, no permanente. También se dispone que la fórmula de juramento será la establecida en la Orden Circular de 9 de junio de 1869.

Iniciado el año 1870 se publicará la última disposición relativa al juramento de la Constitución, en relación al Ministerio de la Guerra, utilizándose como instrumento una Circular General $^{34}$, por la que se establece un plazo final para poder prestar juramento a todas aquellas "clases militares que todavía no lo hubieren verificado", en relación a las disposiciones al respecto emitidas en el mes de junio de 1869, y estableciéndose como plazo de término para la misma el 19 de enero de 1870. Reproduciendo el procedimiento de emisión de los correspondientes certificados de verificación del juramento por parte de las autoridades militares correspondientes y de los representantes consulares en el extranjero en los supuestos de producirse tal como está establecido, el juramento ante ellos. La mencionada circular alcanza tanto a los "individuos del ejército, como a los retirados".

\footnotetext{
${ }^{33}$ Gaceta de Madrid, núm. 174 de 23 de junio de 1869.

${ }^{34}$ Gaceta de Madrid, núm. 9 de 9 de enero de 1870.
} 


\subsection{Ministerio de la Marina}

Tres disposiciones conforman el procedimiento de juramento a realizar por parte de la Armada y sus cuerpos e institutos, el primero con carácter general con fecha de 12 de junio de 1869, el segundo precepto con misma fecha que el anterior pero dirigido específicamente a la Escuadra del Mediterráneo, y la tercera disposición en la que se van a establecer una serie de reglas dirigidas a los oficiales que se encuentran retirados a fin de que lleven a cabo la preceptiva promesa de la Constitución. Por último y de forma breve, en enero de 1870 el Almirantazgo establecerá un plazo final para verificar el juramento a oficiales retirados y jubilados que residan en Madrid.

La Circular general de 10 de junio de $1869^{35}$ va a establecer con carácter general la forma en que habrá de realizarse el juramento de la norma fundamental por los cuerpos e institutos de la Armada, en ciertos aspectos con mucha similitud en lo establecido y ya expuesto anteriormente en relación a las "armas e institutos del Ejército". Tal como ocurre con el Ejército también se establece como fecha el 13 de junio, es decir al día siguiente de la publicación de esta Circular en la Gaceta de Madrid y delimitando también su ámbito dispositivo en la Península Ibérica. El procedimiento que se establece tiene carácter escalonado y sucesivo, señalándose como lugar para verificar el acto, en un primer momento y en relación a determinados oficiales, la "casa - habitación" de los Comandantes generales y Comandantes de las distintas provincias marítimas, además serán estos quienes potestativamente establezcan el horario para llevar a cabo la jura de "Generales, Brigadieres, Jefes y demás Oficiales de todos los cuerpos de la Armada", en esta disposición se hace referencia tanto a los que se encuentran en servicio activo, como aquellos que se encuentran "de cuartel", como también aquellos que se encuentran en ese momento exentos de servicio, cuestión a la que no se hace referencia respecto al Ejército en esta primera fase del procedimiento y ceremonial de juramento.

Se establece que para el mencionado día "el pabellón nacional ondeará en todos los edificios de Marina", así como cada Departamento, llevará a cabo un saludo de 21 salvas, y ese día se "considerará de rigurosa gala".

En un primer acto, el "Secretario de la Comandancia general del Departamento" o ante el "Segundo Comandante de la Provincia", se llevará a cabo la lectura de la Carta Fundamental. Tras la lectura, inmediatamente ante el "General o Jefe de mayor graduación o antigüedad", en el supuesto de que con estos requisitos no lo haya, se dispone que lo hará "su segundo", los comandantes generales y los comandantes de provincias presentes llevarán a cabo el juramento.

La fórmula de juramento utilizada será la siguiente"¿juráis guardar y defender fiel y lealmente la Constitución de la Monarquía española, decretada y sancionada por las Cortes

\footnotetext{
${ }^{35}$ Gaceta de Madrid, núm. 163 de 12 de junio de 1869.
} 
Constituyentes en 1869?" debiendo responder "Sí juro", continuando a la autoridad correspondiente diciendo "Si así lo hiciereis, Dios y la patria os lo premien; y si no os lo demanden". Se trata de la misma fórmula establecida para el Ejército tal como hemos señalado en el apartado anterior referido al Ministerio de la Guerra. Y por lo tanto escalonadamente se utilizará este juramento para el resto de los presentes en este acto.

Tras este acto se va a llevar a cabo un segundo acto que tendrá como referente principal a los Comandantes generales del Arsenales, quienes tomarán juramento a los "Jefes y Oficiales de todos los cuerpos e institutos de la Armada que se hallen a sus órdenes ó tengan destino en aquellos establecimientos". En un tercer momento, se llevará a cabo, en el día y hora que designe el Comandante del Arsenal, el juramento a "los Condestables, marineros, soldados, guardias de arsenales, maestranza, oficiales de mar, patrones y demás clases de los mismos". Se dispone que según las fuerzas presentes se determinará el orden de formación, pero en todo caso lo harán en traje de gala. Este acto que estamos analizando se dividirá secuencialmente por una parte en la lectura de la norma fundamental, pasando seguidamente a la verificación del juramento. Lo que sí establece expresamente la disposición en este apartado es que dicho cato de jura lo presidirá el segundo comandante del arsenal. Será la misma que la del Ejército.

El apartado 40 viene dedicado al cuerpo de Infantería de Marina, donde se establece que los "Coroneles de los regimientos" o en defecto de los coroneles los "primeros Jefes de batallón más antiguos", una vez verificado su juramento ante el Comandante general del Departamento, llevarán a cabo el acto de jura por los procedimientos anteriormente relatados "a la fuerza armada que manden al frente de banderas".

La Circular continúa estableciendo supuestos de verificación del juramento, destacando aquellos casos de los denominados "buques sueltos" y el procedimiento que deberán llevar a cabo sus oficiales para jurar ante quién y en qué forma lo realizarán, lo que sí señala expresamente es la secuencia del acto, en tal sentido se establece que "los individuos" del buque "con las brigadas formadas" escucharán la lectura de la Carta Fundamental, a continuación se leerá lo que la disposición denomina "alocución que circula con esta fecha", entendemos que está haciendo referencia a una circular compeliendo a la Marina que acate la Constitución con fecha 9 de junio de $1869^{36}$. A su vez y dentro del ceremonial del acto que estamos relatando se dará un viva a la Constitución, "rompiendo el engalanado de topes" y recibiendo 21 salvas "los buques que tengan batería cubierta". 0 supuestos, en que ante la inexistencia de "Jefe u Oficial" el acto de juramento se llevará acabo ante una autoridad civil, en estos supuestos tal como se señala ante el "Alcalde Constitucional". En otros supuestos se señala que los "Generales, Jefes y Oficiales" que se encuentren en "puntos en que no resida autoridad de Marina", verificarán el juramento ante la "autoridad Militar".

\footnotetext{
${ }^{36}$ Gaceta de Madrid, núm. 161 de 10 de junio de 1869.
} 
Aunque la Circular circunscribe su aplicación en un primer momento a la Península Ibérica, detalla en la misma los supuestos en los que los oficiales se encuentren con "licencia en el extranjero", en estos supuestos y tal como ocurre en otras disposiciones, podrán llevar a cabo el juramento, ante el representante o Cónsul de España donde se encuentren, debiendo en el plazo de 20 días informar al Almirantazgo. En tal sentido y con carácter general para todos los supuestos será preceptivo levantar acta y remitir la misma al Almirantazgo.

Con carácter particular se establece un apartado específico en relación al "Comandante general del Departamento de Cádiz", a quien se le dispone que deberá de llevar a cabo el juramento a la Constitución ante el Capitán General de la Armada, en el día y hora que este último disponga y como lugar de verificación de la misma su "casa habitación". Como ocurre en otras disposiciones, también se prevén los supuestos de no posibilidad de llevar a cabo el juramento en la fecha establecida, por enfermedad o como señala la circular "u otras imprescindibles", lo llevarán a cabo "tan luego como su salud se lo permita, tomando al efecto la venia del Comandante general del Departamento, o poniéndose de acuerdo con la Autoridad local de Marina del punto en que residan"

Se establece a su vez un plazo excepcional de verificación del juramento en aquellos supuestos en los que no se pueda llevar a cabo en la fecha establecida, trasladándose al domingo 20 de junio de 1869, pero disponiéndose como causa única de dicha excepción, el "no recibirse oportunamente esta circular".

El Almirantazgo, por medio de una Orden de 10 de junio de $1869^{37}$, va a establecer las formalidades y procedimiento en el que se hará la jura de la Constitución por parte de la Escuadra del Mediterráneo, por tanto para la misma se regula específicamente dicho proceder para verificar el juramento, en relación a lo mandatado y dispuesto en la Circular con respecto a los cuerpos e institutos de la Armada anteriormente expuesto. La Orden del Almirantazgo se encuentra dividida por siete apartados, donde como se comprobará se llevarán a cabo dos actos diferenciados de juramento. La disposición establece como fecha el 13 de junio, tal como se mandata para el Ejército y sus institutos y hemos tenido oportunidad de ver en el apartado correspondiente al Ministerio de la Guerra. El apartado 4은 viene a señalar que el mencionado día se "considerará como de gala rigurosa"

Se establece la libertad de elección por parte del Comandante General de la escuadra del Mediterráneo de la hora para que se lleve a cabo un primer acto de juramento, que tendrá lugar en la "cámara del buque de la insignia", donde el Comandante General jurará la Constitución ante todos los comandantes y "segundos" de la escuadra, recibiendo el juramento el "Capitán de Bandera", por tanto en primer lugar jurará el Comandante General, tras el mismo será éste quien tomará juramento al denominado "Capitán de buques".

\footnotetext{
${ }^{37}$ Gaceta de Madrid, núm. 164 de 13 de junio de 1869.
} 
Una vez finalizado este acto, seguidamente se llevará a cabo un segundo acto en cada uno de los buques de la escuadra en donde en una primera parte del acto se realizará la lectura de la Constitución por parte del "segundo Comandante del buque", finalizada la misma las tropas deberán presentar las armas, para seguidamente en segundo lugar pasar al juramento por parte de la tropa, realizado mismo, y en tercer lugar dará lectura a la "alocución del Ministro de Marina", para terminar dando un Viva a la Constitución. Produciéndose en ese mismo instante un "saludo de 21 cañonazos" desde "el buque de la insignia" para que "él y los demás de la escuadra le adornarán con un engalanado de topes".

Destacar que, se llega a disponer una fecha alternativa en el supuesto de que no se pueda llevar a cabo en la fecha señalada del 13 de junio el mencionado acto, el mismo se llevará a cabo el primer día festivo inmediato, pero sólo en el supuesto que el comandante general de la escuadra no reciba "esta comunicación".

Por lo que respecta a la fórmula de juramento no difiere sustancialmente con otras que van a ser utilizadas en este sucesivo proceso de juramento de la Constitución de 1869, así el mismo va a ser el siguiente: "¿Juráis guardar y defender fiel y lealmente la Constitución de la Monarquía española, decretada y sancionada por las Cortes Constituyentes en 1869?" debiendo responder "Sí juro" cuando tiene carácter individual, y "Sí juramos" respecto de la tropa , continuando a la autoridad correspondiente diciendo "Si así lo hiciereis, Dios y la patria os lo premien; y si no os lo demanden". Como se puede comprobar es la misma fórmula que la utilizada por el Ejército".

Destacable es cómo de una manera muy gráfica se establece la disposición de las tropas para este acto, así el apartado 30 describe que; "al efecto, formadas las brigadas en traje de gala, las tropas sobre las armas, y en cubierta todos los oficiales, guardias-marinas y demás individuos de la dotación..." verificándose en dicha disposición el juramento general en cada buque. Para finalizar se establece, como se repite en cada procedimiento en distintas instituciones, cuerpos y funcionarios, la obligatoriedad de levantar y remitir al Ministerio, actas sobre la realización del correspondiente juramento.

Junto a la Orden que acabamos de detallar, en la misma Gaceta de Madrid, se lleva a cabo un anuncio donde se reitera la fecha del 13 de junio de 1869, para prestar el correspondiente juramento, anuncio dirigido tal como el mismo destaca "a fin que llegue a conocimiento de aquellos que no hayan recibido oportunamente la circular expedida con tal objeto".

Por Circular de 2 de julio de $1869^{38}$ se van a establecer una serie de "reglas" para que los jefes y oficiales que se encuentren en situación de retiro puedan efectuar el correspondiente juramento a la Norma Fundamental, la circular está compuesta por 5 apartados, en los que se dispone el procedimiento de juramento en relación a un criterio de territorialidad y residencia, así pues los residentes en Madrid lo llevarán a cabo ante el

\footnotetext{
${ }^{38}$ Gaceta de Madrid, núm. 185 de 4 de julio de 1869.
} 
"Vicepresidente del Almirantazgo", en un espacio fechas concreto (Del 5 al 13 de julio de 1869) y en horario determinado (De 14 a 15 horas). Aquellos que tengan su residencia en lo que la disposición determina como "capitales de departamentos" lo llevarán a cabo ante "los Comandantes generales", quienes serán quienes establezcan la fecha y horario para verificar el juramento.

Ahora bien, los jefes y oficiales que tengan su residencia en "en las capitales de las provincias marítimas y Ayudantías de distrito", la autoridad competente para verificarles el juramento será "la Autoridad de Marina", pero a diferencia de lo anteriormente señalado el plazo para ejecutar dicho acto tiene un carácter muy amplio, se les conceden 30 días para proceder a lo dispuesto. También se incluye el supuesto de inexistencia de Autoridad de Marina donde residan, verificarán el juramento ante "la Autoridad Militar" caso que tampoco haya, ante "el Alcalde" de donde tengan establecida su residencia. Tal como establecen todas las disposiciones que estamos comentando se dispone como medio de prueba de verificación de la promesa, la preceptiva certificación por parte de la autoridad ante quien se hace el juramento.

Iniciado el año 1870 se establece la última disposición ${ }^{39}$ relacionada con la toma del juramento a los miembros de la Armada, el Almirantazgo va a realizar "aviso" y acordará establecer que en los días no festivos hasta el día 19 de enero de 1870, a las "tres y media de la tarde", se extiende la oportunidad de poder verificar el juramento a la Constitución a todos aquellos oficiales y jefes retirados, jubilados y residentes en Madrid y que hasta ese momento no lo hayan podido llevar a cabo. Por tanto se trata de un último llamamiento al respecto, en relación a la Circular relativa a la forma de llevar a cabo el juramento de la Constitución de los jefes y oficiales de los diferentes cuerpos de la Armada retirados del servicio de 2 de julio de 1869.

\subsection{Ministerio de Estado}

Con el fin de reiterar el deber de prestar juramento por parte de los empleados dependientes del Ministerio de Estado, se dispone por Orden de 23 de junio de $1869^{40}$ el procedimiento, supuestos, fórmula de juramento y demás supuestos, por el que se regirán los empleados de dicho Ministerio para llevar a efecto el juramento a la norma fundamental. La Orden desarrolla su contenido en nueve apartados.

Tal como señala el apartado 10 y $2^{\circ}$, con fecha 26 del junio se llevarán a cabo dos actos distintos de juramento, el primero de ellos a las tres de la tarde y en presencia del Ministro de Estado prestarán juramento el Subsecretario, los Jefes de Sección, el Introductor de Embajadores, el Ministro Secretario de las Ordenes, el Comisario general de los Santos Lugares y el Ordenador de Pagos. El lugar para el desarrollo del acto será el Ministerio de Estado y la norma establece de forma expresa que los convocados "al efecto se presentarán

\footnotetext{
${ }^{39}$ Gaceta de Madrid, núm. 16 de 16 de enero de 1870.

${ }^{40}$ Gaceta de Madrid, núm. 175 de 24 de junio de 1869.
} 
de etiqueta". El segundo acto de verificación se realizará a las cuatro de la tarde en el mismo lugar siendo convocados los demás empleados del "Ministerio y de sus dependencias" realizando el juramento en presencia del Subsecretario.

Un tercer y cuarto acto se llevará a cabo el 1 de julio de 1869, a partir de las tres de la tarde son convocados ante el Ministro de Estado, "los ex-Ministros del ramo y los Jefes de Legación cesantes y jubilados residentes en Madrid" para que presten juramento, y seguidamente en otro acto, ante el Subsecretario se verificará la promesa respecto "a los demás empleados cesantes que se hallaren en esta capital". (Apartado 3으). En relación a los jefes de misión en "activo servicio" realizarán el juramento ante "el Secretario de sus Legaciones, y tomarán después juramento á sus subordinados" tal como indica el apartado 4‥

Los siguientes apartados vienen caracterizados por la posibilidad de verificar o llevar a cabo el juramento por escrito, así los "Cónsules y Vicecónsules en una comunicación que dirigirán" al Ministerio de Estado. (Apartado 5ㅇ). Mientras que dicha posibilidad de adhesión por escrito, previa excusa y justificación de no poderlo hacerlo en persona, se traslada también a los empleados cesantes o jubilados residentes en Madrid que se encuentren impedidos por enfermedad (apartado 60) y a todos aquellos empleados ya se encuentren en activo o en situación de cese o jubilación "que se hallen en lugar distante del punto de residencia de cualquier Agente diplomático o consular de España podrán enviar su adhesión por escrito al Ministerio de Estado" tal como indica el apartado 8‥

En cambio la posibilidad de adhesión por escrito no se contempla, con carácter general tal como señala el apartado 7으, a los empleados en "activo servicio" y cesantes ó jubilados que se encuentren en el extranjero, que deberán prestar adhesión a la Constitución ante el representante de España o ante el Cónsul más cercano "al punto en que vivan", debiéndose por dichas autoridades remitir "relación al Ministro de Estado de los que hubieren jurado de este modo", a excepción a lo contemplado apartado 7o anteriormente reseñado.

En relación a la fórmula de juramento, el último apartado (9) dispone que la misma será la siguiente: ¿Juráis guardar y hacer guardar la Constitución de la Monarquía española, promulgada en 6 de junio de este año; juráis haberos bien y fielmente en los deberes que tenéis contraídos, mirando en todo por el bien de la nación? Debiendo contestar "Sí juro" y continuando "Si así lo hiciereis, Dios y la patria os lo premien; y si no os lo demanden, además de exigiros la responsabilidad con arreglo a las leyes"

La Orden finaliza con la advertencia de que la publicación de la misma en la Gaceta de Madrid "servirá de aviso a las personas que deben jurar". 


\section{EL CONSEJO DE ESTADO}

Por medio de una Orden de la Presidencia del Consejo de Ministros de 2 de julio de $1869^{41}$ se dicta la fecha y forma, entre otras cuestiones, por el que han de jurar la norma fundamental los altos funcionarios y empleados del Consejo de Estado. Resultado de la falta de mención expresa en la Orden de 11 de junio de 1869, de los "Presidentes, Consejeros de Estado, Fiscales, Tenientes fiscales, Oficiales y demás empleados de este Alto Cuerpo", y aún señalando que la Orden de 11 de julio los miembros del Consejo de Estado y sus empleados se encontraban "virtualmente comprendidos en la misma" y con el fin de evitar "cualquier duda que pudiera ocurrir" se desarrollan seis artículos donde establece el procedimiento, fechas, y fórmula entre otros aspectos para poder verificar el referido juramento.

Así el artículo 1 dispone que el día 5 de julio de 1869, a las dos de la tarde los presidentes y consejeros, fiscales y tenientes fiscales, incluidos los cesantes y jubilados residentes en Madrid, presten juramento ante el presidente del Consejo de Estado. Tras este primer acto de juramento pero a partir de las tres de la tarde lo verificarán en un segundo acto, los oficiales, auxiliares, aspirantes y demás empleados, incluidos los cesantes y jubilados, pero en este supuesto se realizará en presencia del secretario del Consejo de Estado. (Artículo 2). Por lo que respecta a los "funcionarios de las clases a los que se refieren las dos disposiciones anteriores" que no tengan su residencia en Madrid deberán llevar a cabo dicha promesa ante el Gobernador o el Alcalde popular de la localidad en la que se encuentren, tal como señala el artículo 3. Se entiende que para este supuesto son de aplicación las fechas y horas anteriormente señaladas.

Por lo que respecta a los "funcionarios cesantes y jubilados cualquiera que sea su categoría", pero con residencia en el extranjero, deberán verificar el juramento, tal como expresa el artículo 5, ante el representante de España "en el punto en que se hallen", desarrollando el precepto una serie de requisitos de carácter formal que se deberán cumplir tales como en el plazo de un mes, la remisión del correspondiente oficio por escrito al presidente del Consejo de Estado, y en los supuestos de lugares donde no exista "Representación" pues deberán llevar a cabo "de oficio su adhesión al Código Fundamental" y además en el mismo plazo anteriormente reseñado remitir la misma al presidente del Consejo de Estado al igual que en el supuesto anterior. En relación con aquellos que por enfermedad o cualquier "otra causa legítima" no puedan verificar el juramento se aplica lo preceptuado anteriormente en términos generales, esto es, en el plazo de un mes y "prestando de oficio su adhesión" remitirán a la presidencia la misma, pero en este caso deberá de ir acompañada del correspondiente justificante de padecer enfermedad o cualquier otra causa legítima que motive dicha opción.

Finalmente señalar la fórmula de juramento elegida para los miembros del Consejo de Estado y que establece el artículo 4 de la siguiente forma: “¿Juráis guardar y hacer guardar la Constitución de la Monarquía española promulgada el 6 de junio de 1869?,

\footnotetext{
${ }^{41}$ Gaceta de Madrid, núm. 184 de 3 de julio de 1869.
} 
debiendo contestarse, "Sí juro" y continuando señalando "Si así lo hiciereis, Dios y la patria os lo premie; y si no os lo demande, además de exigiros la responsabilidad con arreglo a las leyes".

Con fecha 4 de julio de 1869, por medio de un Anuncio Oficial de la Secretaría General del Consejo de Estado ${ }^{42}$, se lleva a cabo la citación de todos los funcionarios cesantes y jubilados "comprendidos en la Orden de la Presidencia del Consejo de Ministros de fecha 2 del actual, publicada en la Gaceta de ayer", para que tal como señala dicha disposición el lunes 5 de julio a la hora señalada "se sirvan concurrir" para llevar a efecto el juramento "a la Constitución de la Monarquía promulgada en 6 de junio último".

\section{LA LEY DE 18 DE DICIEMBRE DE 1869}

Toda esta sucesiva y profusa publicación de disposiciones respecto al juramento de la Constitución tendrá como remate final la Ley de 18 de diciembre de $1869^{43}$, la cual contiene un solo artículo por el cual se establece por una parte, un plazo final para poder llevar a cabo el juramento, el plazo que se establece es de un mes, por tanto todos aquellos que no hayan verificado dicha jura o en su caso no acrediten haberlo realizado, se establece una consecuencia expresa ante ello y que afecta de forma sustancial a los mismos, transcurrido dicho plazo, serán declarados "sin derecho a desempeñar destinos y funciones públicas y al percibo de haberes de retiro, de cesantía y jubilación". Por tanto se trata de una norma que limita y elimina sus derechos básicos como empleados públicos.

\section{LA IGLESIA Y EL JURAMENTO DE LA CONSTITUCIÓN DE 1869}

\subsection{La Regulación de la jura de la Constitución por parte del clero}

La regulación normativa de la jura del clero vendrá establecida por un Decreto ${ }^{44}$ de 17 de marzo de 1870 con carácter general y una Circular ${ }^{45}$ posterior con fecha de 13 de abril de 1870. Como la propia Exposición del Decreto señala "no es una novedad el juramento del clero a la Constitución de 1869. También en su tiempo prestó adhesión tan solemne a la de 1812 y a sus reformas de $1837^{46}$ y $1843^{47} \ldots$... Por tanto, se trata de una disposición ya establecida en otros procesos constituyentes y por lo tanto no desconocida. En tal sentido la Exposición a la que se alude viene a señalar que la Ley Fundamental que se jura no contiene en su artículo "que se oponga a los preceptos religiosos", afirmando que "la libertad de cultos que consagra es un derecho político que protege en el orden temporal la conciencia del ciudadano...".

\footnotetext{
${ }^{42}$ Gaceta de Madrid, núm. 185 de 4 de julio de 1869.

${ }^{43}$ Gaceta de Madrid, núm. 353 de 19 de diciembre de 1869.

${ }^{44}$ Gaceta de Madrid, núm. 78 de 19 de marzo de 1870.

${ }^{45}$ Gaceta de Madrid, núm. 104 de 14 de abril de 1870.

${ }^{46}$ Gaceta de Madrid, núm. 930 de 19 de junio de 1837.

${ }^{47}$ Gaceta de Madrid núm. 3363, de 29 de noviembre 1843.
} 


\subsection{Decreto por el que se regula el juramento del clero a la Constitución del Estado, con carácter general}

Por Decreto de 17 de marzo de 1870 se va a establecer el juramento del clero a la norma fundamental de 1869 , el cual se compone de seis artículos donde se establece pormenorizadamente distintos aspectos relacionados con la jura. En tal sentido se hace una delimitación territorial en relación a quién debe prestar juramento, así el artículo 1 señala que los arzobispos y "reverendos obispos" presentes en Madrid prestarán juramento ante el Ministro de Gracia y Justicia en el "término del mes siguiente a la fecha de este decreto de fidelidad a la Constitución vigente", y estableciendo además la fórmula de juramento que será la siguiente: "¿Juráis por Dios y los Santos Evangelios guardar la Constitución de la monarquía Española?" debiendo contestar "Sí juro", concluyendo la fórmula con "si así lo hiciereis Dios os premie, y si no os lo demande". Por lo que respecta a arzobispos, obispos, "Cabildos metropolitanos, sufragáncos y colegiales", cuyo ámbito territorial corresponda a capitales de Audiencia, tendrán también un mes para verificar el juramento los que se encuentren en la "Península e islas adyacentes", ampliándose dicho plazo para aquellos que se encuentren en Canarias a dos meses. Respecto a la fórmula de juramento será la misma llevándose a cabo ante "los Regentes de aquellos tribunales" y en presencia de un "Secretario de gobierno". Todos aquellos que residan en otras poblaciones "lo prestarán dentro de los mismos plazos" pero en este supuesto ante el juez de primera instancia y caso de existencia de varios de ellos, ante el juez decano y en presencia del correspondiente secretario de gobierno, tal como expresa el artículo 2.

Por lo que se refiere a los eclesiásticos, "cualquiera que sea su jerarquía", que se encuentren ausentes de la "Península", tal como establece el artículo 6, prestarán juramento en el plazo de 2 meses, al igual que los que residían en Canarias, ante el Representante de España y en su defecto Cónsul de su lugar de residencia.

El Decreto contiene en los artículos 4, 5 e inciso final del artículo 6, se establecen una serie de obligaciones de carácter procedimental y administrativo, así como de medidas para cumplir con el juramento en los supuestos de enfermedad e impedimento, por el cual los regentes, jueces de primera instancia y de paz elevarán certificación de las actas del juramento libradas por los secretarios, "por el conducto ordinario" y dirigida al Ministerio de Gracia y Justicia, y cumplidos los plazos que se han señalado con anterioridad. Lo mismo deberán de realizar en el plazo de quince días el Representante de España o el Cónsul una vez recibidas las actas de juramento.

El artículo 3 vienen a desarrollar, en relación a lo expuesto, ciertas especificidades en respecto a los que denomina como "individuos del clero parroquial y demás eclesiásticos exclaustrales y dependientes de todas las clases de catedrales, colegiatas, parroquias y capillas que por razón de su cargo u oficio eclesiástico" y aquí su especificidad, "perciban haber del presupuesto del Estado" y además residan en el distrito municipal a la que corresponda la capital del juzgado de primera instancia, prestarán juramento ante las mismas autoridades y plazos establecidos en el artículo 2 del Decreto. En el supuesto de que 
en el lugar que residan haya más de un juzgado el juramento se verificará ante el juez decano y por último aquellos que residan en distritos municipales que no sean capitales de juzgado lo prestarán ante el juez de paz asistido por el correspondiente secretario.

Para finalizar y en relación a los supuestos establecidos en el artículo 5, se establece por parte de los regentes, jueces de primera instancia y de paz, la adopción de medidas necesarias para que "los individuos y dependientes del clero que no estando ausentes de la Península" pero que en este caso se encuentren enfermos y "legítimamente impedidos", puedan dentro de los plazos que se han establecido cumplir con lo señalado en el Decreto, pero con la apreciación de que se deberá estar a las circunstancias particulares de cada caso.

\subsection{Circular dictaminando varias disposiciones relativas al juramento que ha de prestar el clero castrense}

Por Circular de 13 de abril de 1870, y con el fin de dar cumplimiento al Decreto que en el anterior apartado hemos analizado, y "de la jurisdicción exenta del clero castrense", se resuelve en seis artículos distintas disposiciones en relación al juramento del clero castrense. En primer lugar, indicar que se establece como fórmula de juramento la misma dispuesta en el Decreto: "¿Juráis por Dios y los Santos Evangelios guardar la Constitución de la monarquía española?" debiendo contestar "Sí juro", concluyendo la fórmula con "si así lo hiciereis Dios os premie, y si no os lo demande". Y así lo deberá de prestar el vicario general castrense, siendo tal el denominado Reverendo Patriarca de las Indias, al que se le señala un plazo de dos meses para prestar juramento a la fecha de la Circular, pudiendo verificarla de tres formas diferentes, en tal sentido lo podrá llevar a cabo ante el Ministro de la Guerra, y dado el caso que reside en Roma "actualmente", podrá verificarlo por delegación ante el encargado de negocios del Gobierno en Roma, o ante el representante de España o cónsul "del punto al que pudiera trasladarse". Por tanto, vemos una triple opción a la que el vicario general castrense tiene posibilidad de acogerse para prestar juramento.

\section{CONCLUSIONES}

Del análisis del presente estudio se pueden deducir varias conclusiones en relación al tema tratado, por una parte la trascendencia del acto de promulgación y juramento de la Constitución de 1869, definidora de un nuevo régimen político, como norma fundamental del mismo, y el acto que se llevará a cabo el 6 de junio de 1869 como instrumento de legitimación y de exaltación, no cabe duda que el hecho de producirse la promulgación en el pórtico de las Cortes ante la ciudadanía y en presencia de las más altas tiene un claro sentido y función, cual es la de trascender y legitimar al nuevo régimen. Ello a su vez complementado con los distintos actos populares de promulgación realizados por todo el territorio nacional. Como ya hemos indicado, los sucesivos actos que se producirán en ese mes de junio, van a tener todos esencialmente estas características.

Por otra parte y respecto del juramento hay que destacar la profusa e ingente elaboración normativa a lo largo de un año en relación al mismo, con tal exhaustividad hacia 
quienes va dirigido, ya sea personal de los ministerios, institutos y cuerpos de las fuerzas armadas, funcionarios de todas las ramas ya sean cesantes, jubilados, ausentes o estén enfermos o en el extranjero, así como respecto de otras instituciones, ya se encuentren en Madrid, en las distintas provincias, como en las Islas Canarias, Cuba, Puerto Rico o Filipinas, etc. Por tanto un amplio abanico de destinatarios a los que se les conminará a prestar juramento a la Constitución de 1869, y desarrollándose para ello un procedimiento y ceremonial para que puedan verificar la jura,. Destacar también que no se utiliza una fórmula única y genérica de juramento, como se ha podido comprobar, se establece un modelo con numerosas variantes, a tenor de lo establecido en las distintas disposiciones.

Como última conclusión podemos señalar las graves consecuencias de no verificar dicha formalidad, además dispuestas en una norma con rango de Ley, desarrollado en un solo artículo de carácter breve, pero que establece tales consecuencias que afectan directamente a la no posibilidad de poder desarrollar sus funciones y consecuentemente la pérdida de sus derechos retributivos. Al igual que otros actos que se celebrarán en ese mes de junio de 1869, hay que destacar la capacidad de organización en tan breve espacio de tiempo de los mismos de manera consecutiva.

\section{BIBLIOGRAFÍA}

AJA, E. Y SOLÉ TURA, J. (1988): Constituciones y períodos constituyentes en España (18081936). Siglo Veintiuno Editores.

ALEJANDRE GARCÍA, J.A., GACTO FERNÁNDE, E., GARCÍA MARÍN, J.M. (1982): El Derecho Histórico de los Pueblos de España (Temas para un curso de Historia del Derecho). Universidad de Madrid, Facultad de Derecho, Sección de Publicaciones.

ALVARADO PLANAS, J. (COORD.), MONTES SALGUERO, J., PÉREZ MARCOS, R.M. (COORD.), SÁNCHEZ GONZÁLEZ, D.M. (2002): Lecciones de Historia del derecho y de las Instituciones, Vol. I y II. UNED

BOLETín OFICIAL DEL ESTADO. (2006): El Boletín Oficial del Estado. Testimonio de la Historia.

BULDAIN JACA, B. (COORD.), ELIZALDE, M.D., GUERRERO, A.C., SISINIO PÉREZ, J., RUEDA G., SUEIRO S. (2011): Historia contemporánea de España 1808 - 1923. Editorial Akal S.A.

CASADO TRIGO, M. (2016): Historia del protocolo en las Cortes Generales Españolas. Editorial Sanz y Torres.

DE DIEGO GARCÍA E. Y RUIZ DE AZÚA E. (1994): Historia de España, Volumen XII. Instituto Galach.

DE LA FUENTE MONGE, G. (2000): Los Revolucionarios de 1868, Élites y Poder en la España Revolucionaria. Marcial Pons Historia. 
DE URBINA, J.A. (2001): El Gran Libro del Protocolo. Temas de Hoy.

FERNÁNDEZ SEGADO, F. (1986): Las Constituciones Históricas Españolas. Editorial Civitas.

FUENTES LAFUENTE, C. (2010): Protocolo Oficial. Las instituciones españolas del Estado y su ceremonial. Ediciones Protocolo.

GARCÍA CORTÁZAR, F., y GONZÁLEZ VESGA, J.M. (1994): Breve Historia de España. Alianza Editorial.

GARCÍA DELGADO, J.L., JOVER ZAMORA, J.M., MARTÍ, C., RUIZ, D., TORTELLA CASARES, G. (1988): Historia de España dirigida por Manuel Tuñón de Lara, Tomo VIII, Revolución Burguesa, Oligarquía y Constitucionalismo (1834 - 1923). Editorial Labor S.A.

GONZÁLEZ CASANOVA, J.A. (1982): Teoría del Estado y Derecho Constitucional. Vicens Universidad.

LÓPEZ - NIETO Y MALLO, F. (2000): Honores y Protocolo. El Consultor.

JULIÁ. S. Y MARTORELL, M. (2013): Manual de historia política y social de España (18082011). Editorial UNED.

MEDINA ÁVILA, C.J. (2016): Manual de simbología y emblemática oficial. Editorial Síntesis.

MEDINA ÁVILA, C.J. (2016): Manual de protocolo y ceremonial militar. Editorial Síntesis.

PÉREZ PRENDES, J.M. Y DE AZCÁRRAGA, J. (1993): Lecciones de historia del derecho español. Editorial Centro de estudios Ramón Areces, S.A.

PORTUGAL BUENO, MC. (2016): Guía de protocolo y derecho premial civil. Editorial Síntesis.

RICO LINAGE, R. (1999): Constituciones Históricas. Publicaciones de la Universidad de Sevilla, Manuales Universitarios.

SÁNCHEZ ARCILLA-BERNAL, J. (1994): Historia de las Instituciones Político - Administrativas Contemporáneas (1808-1975). Dykinson.

SÁNCHEZ GONZÁLEZ, D.M. (2011): Fundamentos del ceremonial y del protocolo. Editorial Síntesis.

SÁNCHEZ GONZÁLEZ, D.M. (2017): Manual de protocolo oficial y derecho ceremonial del Estado. Editorial Síntesis.

SÁNCHEZ GONZÁLEZ, D.M., GÓMEZ REQUEJO, M.V., Y PÉREZ MARCOS M.R. (2015): Historia del ceremonial y el protocolo. Editorial Síntesis.

TOMÁS Y VALIENTE, F. (1990). Manual de historia del derecho español. Editorial Tecnos. 
TORRES DEL MORAL, A. (1991): Constitucionalismo Histórico Español. Atomo Ediciones.

VILARRUBIAS, F.A. (1997): Protocolo, Ceremonial y Heráldica en las Corporaciones Públicas y las Empresas. Universidad de Oviedo.

VILARRUBIAS, F.A. (2010): Tratado de Protocolo, Heráldica, Vexilología y Emblemática Nacional e Internacional. Ediciones Nobel.

\section{ARCHIVOS, RECURSOS BIBLIOGRÁFICOS Y DIGITALES}

Biblioteca Central. Universidad de Las Palmas de Gran Canaria.

Biblioteca Nacional. Madrid

Archivo del Congreso de los Diputados. Madrid

Congreso de los Diputados. Diario de Sesiones. Serie histórica.

http://www.congreso.es/est_sesiones/

Boletín Oficial del Estado. Gazeta: Colección histórica.

https://www.boe.es/buscar/gazeta.php

Senado de España. Archivo. Períodos Constitucionales.

http://www.senado.es/web/conocersenado/senadohistoria/periodosconstitucionales/index. $\underline{\text { html\#2 }}$

Biblioteca Virtual de Prensa Histórica. Ministerio de Educación, Cultura y Deporte.

http://prensahistorica.mcu.es/es/estaticos/contenido.cmd?pagina=estaticos $\% 2$ Fpresentacio $\underline{\mathrm{n}}$

Biblioteca Nacional de España. Hemeroteca Digital.

http://www.bne.es/es/Catalogos/HemerotecaDigital/

Jable. Archivo de Prensa Digital.

$\underline{\text { https://jable.ulpgc.es }}$ 